\title{
Visual processing in migraine
}

\begin{tabular}{|r|l|}
\hline Journal: & Cephalalgia \\
\hline Manuscript ID & CHA-00350-RE-2015.R1 \\
\hline Danuscript Type: & Review \\
\hline Complete List of Authors: & $\begin{array}{l}\text { O'Hare, Louise; University of Lincoln, School of Psychology } \\
\text { Hibbard, Paul; University of Essex, Department of Psychology; University of } \\
\text { St Andrews, School of Psychology and Neuroscience }\end{array}$ \\
\hline Key Words: & Migraine, Visual perception, Signal processing model \\
\hline & \\
\hline
\end{tabular}

SCHOLARONE $^{\text {'x }}$

Manuscripts 


\title{
Visual processing in migraine
}

Louise O'Hare ${ }^{\mathrm{a}}$, Paul B. Hibbard ${ }^{\mathrm{b}, \mathrm{c}}$

${ }^{\mathrm{a}}$ School of Psychology, College of Social Science, University of Lincoln, Brayford Pool, Lincoln, LN6 7TS, LOHare@lincoln.ac.uk, corresponding author

${ }^{\mathrm{b}}$ Department of Psychology, University of Essex, Wivenhoe Park, Colchester, Essex, CO4 3SQ, phibbard@essex.ac.uk

${ }^{\mathrm{c}}$ School of Psychology and Neuroscience, University of St Andrews, St Andrews, Fife, KY16 9JP.

\begin{abstract}
Background

Migraine is a common neurological condition that often involves differences in visual processing. These sensory processing differences provide important information about the underlying causes of the condition, and for the development of treatments.

Review of Psychophysical Literature

Psychophysical experiments have shown consistent impairments in contrast sensitivity, orientation acuity, and the perception of global form and motion. They have also established that the addition of task-irrelevant visual noise has a greater effect, and that surround suppression, masking and adaptation are all stronger in migraine.

\section{Theoretical Signal Processing Model}

We propose utilising an established model of visual processing, based on signal processing theory, to account for the behavioural differences seen in migraine. This has the advantage of precision and clarity, and generating clear, falsifiable predictions.

\section{Conclusion}

Increased effects of noise and differences in excitation and inhibition can account for the differences in migraine visual perception. Consolidating existing research and creating a unified, defined theoretical account is needed to better understand the disorder.
\end{abstract}

\section{Keywords}

Migraine, Vision Perception, Signal Processing Model

\section{Introduction}

Migraine is a debilitating and common condition that, by definition, is associated with differences in visual perception. The International Headache Society criteria for classifying migraine list photophobia, an increased sensitivity to light, as one of the key signs of a migraine attack, alongside a severe headache lasting 4-72 hours and nausea/vomiting (1). Some people with migraine report visual triggers of attacks $(2,3$, 4), and are particularly sensitive to light stimulation during an attack (5). In some people, a migraine attack is preceded by a set of sensory, motor or speech disturbances known as the migraine aura. Although these disturbances can be in any 
modality, for example auditory, olfactory, the aura is often visual-, which is experienced in $57 \%$ of cases (6). (1). The visual aura consists of a fortification pattern surrounding a central scotoma.small geometric pattern, known as a fortification pattern. This expands over a short period of time, typically around 20 minutes, to cover a large area of the visual field. The fortification pattern surrounds a central scotoma, or hole in the visual field, which appears to scintillate. Illustrations of these patterns can be seen in $(8 \underline{7}, \underline{8} 9,109)$. Other phenomena include patterns such as tunnels and spirals, flashes of light (phosphenes), changes in apparent scale (micropsia and macropsia), and a disjointedness of the visual image, such that objects appear as they do in Cubist paintings (87).

Photosensitivity is aversion to light, which is a feature of migraine. Photosensitivity is increased in migraine (e.g. $13 \underline{10}$ ). $87 \%$ of people with migraine indicated that pain could be induced by light stimulation, and pain thresholds were lower than those for a control group (1411). Long wavelength, reddish light $(398-503 \mathrm{~nm})$ caused the most discomfort for people with migraine (1512). As the trigeminal ganglion responds to light, it could account for some of the photosensitivity in migraine (1613). Applying an ice-block to the centre of the forehead, so as to induce trigeminal pain, reduced visual discomfort thresholds for people with migraine $(17,18,1914,15,16)$. A thalamic pathway for the exacerbation of migraine headache by light has also been proposed ( 2017 ). There is evidence of a possible mechanism for this, as the same PET activation from light and pain in controls has been found, as from light alone in | migraine (211ㅇ).

Spatially and temporally periodic stimuli are particularly uncomfortable and can induce migraine attacks (2). Stripes caused discomfort for $82 \%$ of people with | migraine, compared with only $18 \%$ of a control sample (2219). The tendency of a striped pattern to cause discomfort depends on its spatial frequency, or the width of the stripes (Figure 1). Striped patterns of around 3 cycles/degree cause greater discomfort than either higher or lower frequencies (2320). People with migraine reported more illusions, and experienced greater pattern glare, when viewing 1.2 cycles/degrees gratings, which was accompanied by greater fMRI BOLD response (2124). The temporal properties of a stimulus, as well as its spatial properties, affect discomfort judgements. Haigh and colleagues (2225) found that the contrast threshold at which 2 cycles/degree gratings started to become uncomfortable to view was lower in people with migraine than in controls. Drifting and vibrating stimuli were found to be more aversive than static stimuli. People with migraine also report greater discomfort scores for a large, uniform field flickering at $10 \mathrm{~Hz}(26,27 \underline{23,24})$.

In between attacks (interictally) people with migraine tend to show differences on tests of visual processing compared with control groups.

There is a substantial body of research into sensory processing in migraine, using clinical, neurophysiological and electrophysiological approaches. This research has established clear differences in visual perception in migraine, accompanied by differences in neural responses to visual stimuli. This has led to the proposal of several theoretical accounts of migraine that are linked to abnormalities in sensory processing. In turn, these accounts have suggested that the visual cortex in migraine is either hyperresponsive or hyperexcited, does not habituate to stimuli, and shows a reduction in the degree of inhibitory interactions between neurons. The distinctions between these accounts can be very fine, and can turn on the precise definition of key 
terminology, which varies between groups of researchers. The current article provides a review of the literature on visual processing in migraine, and a novel theoretical account that brings together a number of strands of research, and builds on previous explanations. We conclude that, when viewed as a whole, visual processing differences in migraine can be characterised as showing greater effects of internal noise. This term 'noise' is used here to refer broadly to any activity in the visual system that can potentially hinder performance on a given perceptual task, and covers a wide range of sources and types of such activity. As such, we introduce a mathematically defined model, based on signal detection theory, in order to help describe and explain the nature of differences in visual perception in migraine. In this review, we concentrate on studies that have researched differences on psychophysical tasks. These differences are accompanied by differences in neural activity in migraine. We do not discuss these in detail, as they have recently been reviewed $(6 \underline{62})$.

\section{| The characteristics of migraine}

\section{Prevalence and diagnesis \\ Migraine is one of the most common neurological disorders, estimated to affect around $8 \%$ of men and $18 \%$ of women (7). It is a heterogeneous condition; the manifestation of particular symptoms, and the duration and severity of these symptoms, is highly wariable between individuals, as is the time period between attacks (5). Related disorders, including cluster headache (bouts of frequent, severe headaches) and tension headache, further complicate the issue of diagnosis, which requires accurate recognition of the relevant clusters of symptoms. The International Headache Society diagnostic criteria for migraine (1) require at least five attacks of a lateralised, pulsating headache, lasting four or more hours, which disrupts daily activities and is aggravated by physical activity. The headache is to be accompanied be at least one of the following: nausea and/or vomiting, photophobia (a heightened sensitivity to light) and phonophobia (a heightened sensitivity to sounds).}

| Migraine Aura

Approximately $40 \%$ of people with migraine experience sensory disturbances, known as aura, which develop over a period of five to twenty minutes and last for an hour (7). These disturbances can be across any modality, but the most commonly reported is visual, which is experienced in $57 \%$ of cases (7). While there is considerable variation in the nature of the aura experienced, there are a number of recurring trends. Many people with visual aura report that it begins as a More generally, an increased prevalence of sensory disturbances has been found in migraine both with and without aura (11).

\section{Migraine Triggers}

It is possible to trigger migraine with external stimuli, (12). Triggers for migraine are highly idiosyncratic. A large study of 1750 people (3) found stress to be the most common environmental trigger, reported by nearly $80 \%$ of respondents. Other factors included the hormonal cycle, weather, too little (or too much) sleep, specific foods, 
alcohol, fasting, and exercise. Of particular interest here, light is a common trigger, affecting $38 \%$ of people with migraine.

Photosensitivity and visual discomfort in migraine

Gyclic nature of the disorder

There are clear changes in sensory processing in migraine across the cycle between one headache and anotheracross the migraine cycle, seen in both behavioural performance and electrophysiological recordings (e.g. 2826). This is an issue that should be considered when evaluating migraine group performance. Although mMany studies make efforts to avoid testing near the headache event (e.g. 2927), some aim to investigate these cycle effects directly (e.g. 2830). Results are not always unidirectional - Results of electrophysiological studies are also affected by the migraine cycle _ somesome electrophysiological studies find more pronounced differences in migraine compared to control in the days before an attack $(31,32$, $3329,30,31)$. However, this is not always the case. It has been shown that, whereas other studies showed EEG activity VEP habituation normalises just before, and during, a migraine atack (3432), and only during, a migraine attack (33). Normalisation of neural activity has been found in migraine compared to control groups during an attack (35). Other researchers only found differences in the EEG response 10 days after the migraine attack (3634)._To further complicate matters, some researchers find cycle effects only for behavioural performance measures, not EEG responses (37하). Not all studies measure across the migraine cycle, and aAll the psychophysical studies reviewed here have excluded individuals close to a migraine attack. Therefore, while it is important to understand these migraine cycle effects, many studies have been careful to test individuals away from an attack, therefore reducing the impact of these effects on the experimental findings. However, it should be borne in mind that, for one-off experiments, migraine cycle effects are likely to add variability to the results.

\section{Visual processing differences in migraine}

The visual discomfort and visual aura that can occur in migraine, together with the fact that visual stimulation can trigger a migraine attack, and the association with increased neural activity, all suggest differences in visual processing in migraine. Such differences have been found across many domains, for example the perception of colour $(36,37,38,3938,39,40,41)$, binocular vision (4240) and the higher level visual processing involved in the perception of facial expressions (4ㅌ). Here, we concentrate on studies of low-level visual processing in migraine.

\section{Contrast sensitivity}

Contrast sensitivity is the minimum contrast required to detect or discriminate a stimulus, and several studies have shown poorer contrast sensitivity in migraine. The results do however vary between studies. For example, some studies found reduced contrast sensitivity in people with migraine compared to a control group, for static gratings with a spatial frequency of four cycles/degree, $(4,44 \underline{2})$ while others do not: others did not find differences when using Gabor stimuli of the same frequency 
(4543) (gratings in a Gaussian envelope, an example of a Gabor stimulus is shown in Figure 1). Similarly, McColl and Wilkinson (4644) found no difference in contrast detection thresholds for a small (2 degrees), 3 cycles/degree difference of Gaussian target. Some studies report differences across a range of spatial frequencies. For | example, Yenice and co-workers (4745) found reduced contrast sensitivity in migraine at all spatial frequencies between 1.5 and 18 cycles/degree for small (1.7 degrees) static sinusoidal stimuli. Others report impairment at particular frequencies.

| For example, (4846) found no difference at the midrange (3cpd), but poorer performance in migraine for all other (higher and lower) frequencies tested. Meanwhile, reduced sensitivity was particularly evident at low spatial frequencies, under both photopic (well-lit) and scotopic (darkened) lighting conditions (49ㄴㄱ). (5048) showed poorer performance in migraine with large stimuli. Other researchers also showed no group difference for foveally presented stimuli, but poorer sensitivity in migraine for peripherally presented stimuli (2927). Braunitzer and colleagues (5149) found reduced contrast sensitivity in children with migraine, demonstrating the possibility of the progression of the disorder. A summary of the contrast sensitivity studies is shown in Table 1. This outlines the main points about stimuli, presentation method and migraine participants.

To summarise, some studies have found reduced contrast sensitivity in migraine, but this is not unanimous. The variability in results across studies is likely to reflect the heterogeneity of the condition, the migraine cycle effects discussed, the very different stimuli and methods used in different studies, and the small sample sizes often employed. Differences in stimuli and psychophysical methods, in particular, make it difficult to compare studies fairly. Overall, there does seem to be some evidence for poorer contrast sensitivity in migraine.

\section{Inhibitory interactions}

The activity of visual neurons is determined by both direct stimulation by external sources, and by inputs from other neurons, which can be both inhibitory and excitatory. Some of these interactions occur at the scale of the receptive fields of individual neurons. For example, the orientation selectivity of individual neurons depends on both feed-forward input from the lateral geniculate nucleus (LGN), and inhibitory input from other cortical neurons $(52,53,5450,51,52)$. Suppression effects from surrounding units also operate on larger scales, for example those that are responsible for contrast normalisation (5553) and surround suppression (5654). Evidence for this has been found in V1 single-cell recordings in macaques (57 $\underline{55})$. It has also been suggested that V1 cells respond to entire feature combinations (e.g. a red, vertical line). This will allow for suppression not only across single characteristics of the target, but across combined features. This iso-feature suppression has been proposed as an important mechanism in visual search tasks (5856). In addition, inhibitory and excitatory interactions form the basis of the mechanisms that group individual features into extended contours, and coherent global form (5957). If lateral inhibition processes are reduced in migraine, there will be differences on performance in these tasks compared to control populations.

\section{Orientation acuity}


Orientation discrimination is thought to rely on lateral inhibition between neighbouring neural units $(52,53,5450,51,52)$. Therefore, differences in inhibitory processes could lead to different performance in migraine. Orientation acuity was measured with a derivative of Gaussian stimulus, and a sinusoidal grating, both foveally ( 9 cycles/degree) and peripherally (3.6 cycles/degree). No significant | differences in orientation thresholds were found (6058). Other researchers found poorer sensitivity to orientation differences for foveally presented Gabor patches with a spatial frequency of 0.5 cycles/degree, but not for peripherally presented stimuli, or | those with a spatial frequency of 4 cycles/degree (6159). Researchers measured orientation sensitivity using a four cycles/degree Gabor patch, and a virtual line, | defined by the presentation of two circles presented either side of fixation (45녀). Poorer orientation discrimination was found for both stimuli when they were at | oblique orientations, but not when they were horizontal or vertical (4543). Poorer performance with the virtual line stimuli is interesting because is indicates that the deficit in orientation acuity occurs for stimuli that are processed in extrastriate cortex, and is not therefore restricted to V1, in other words, the deficits are found in higher visual areas also.

\section{Surround Suppression}

Battista and colleagues ( $62 \underline{60})$ measured the size of the Chubb illusion ( $63 \underline{61})$, in which the apparent contrast of a central region is reduced in the presence of a high contrast surround (Figure 2). They found a greater effect in migraine for moving stimuli ( 2 cycles/degree grating, drifting at 2 cycles/second), but not for static stimuli (4 cycles/degree grating). These results show a greater surround suppression effect in migraine, but only for moving stimuli.

\section{Visual Search}

In simple visual search tasks, observers are asked to detect a target that differs in some way from a background of distracters, and it has been proposed that this relies on interactions at the feature-level, called iso-feature-suppression (58 $\underline{56}$ ). The difference between the target and the distracting elements determines the ease with which the task can be completed. For example, the elements might be lines, with the target differing from the distractors in orientation. People with migraine are able to complete search tasks more quickly than others, while maintaining the same level of accuracy (6362). However, other studies that have assessed visual search performance in migraine have failed to find any such improvements $(64,65,66 \underline{63}, 64,65,49 \underline{38})$. There is thus no evidence that performance on visual search tasks is different in migraine.

\section{Summary of inhibitory processes}

Behavioural effects that rely on lateral inhibition processes (e.g. orientation tuning, suppression effects, and visual search) are on the whole unimpaired in migraine.

\section{Masking effects in migraine}


Adding visual noise to a stimulus can cause masking, reducing the observer's ability to accurately detect or discriminate a target. A noise mask can take many different forms, and can affect performance by either spatially or temporally disrupting processing. Masking is often accounted for by considering the fact that the mechanisms responding to the target stimulus will also respond to the masking noise | (6766). However, even when the target and mask activate separate mechanisms, masking can still result from interactions between them, as occurs in surround suppression (6867). Baker and Meese noted that some studies of masking might in fact be demonstrating the effects of surround suppression (696). This has important consequences in the interpretation of masking effects in migraine.

\section{Direct visual masking}

Direct masking occurs when a mask is presented at the same time, and in the same spatial location, as the target stimulus. Greater masking effects have been found in migraine compared to control groups, when mask (grating) and target (Gabor) were presented simultaneously (4644). Poorer performance has been found in migraine to detect a small circular target against a random noise background in migraine (70 $\underline{69}$ ). These results were replicated (71므), suggesting that task-irrelevant backgrounds can create greater interference with the successful detection of target stimuli in migraine groups.

\section{Metacontrast masking}

The accuracy with which a target can be detected can be affected by the presence of other, task-irrelevant stimuli, even if the two do not overlap in time or space. The effects of such metacontrast masking have been assessed in migraine. Increased | masking has been shown for $\mathrm{MA} \Theta$ compared to $\mathrm{MO}$ and control $A$ groups, both when a mask was presented at the same time as the target, or with a delay of up to $156 \mathrm{~ms}$ | (7271). Since this study did not include a control in which the target was presented without a mask, it is not known whether the improved performance was due to a decrease in masking, or simply to greater accuracy in the target-detection task. This

| experiment was replicated (7372), this time including forward masking conditions, in which the mask preceded the target, and a condition in which forward (mask presented before the stimulus) and backward (mask presented after the stimulus) masking were present. As found previously (7271), better performance was associated with migraine, both with and without aura (7372). This difference reflected an overall higher level of performance in the migraine groups, rather than a reduction in metacontrast masking; when baseline performance in the absence of a mask was taken into account, no difference in the degree of masking was observed. Metacontrast masking was studied masking using a vertical bar target, with both forward and backward masking (74그). However, in contrast with previous work (721ㅡ), no difference in performance associated with migraine was found (74 $\underline{73})$. It is notable that, across these studies, although no evidence for increased meta-contrast masking was found, baseline performance was better in the migraine group. 
Greater backward masking was found in migraine when participants were asked to detect small deviations of a contour from circularity (7574). The main difference between this study and the others discussed here is that it assessed the effects on the just-noticeable differences in the target shape, rather than simply its presence or absence. Thus, the effects of masking are very much dependent on the type of mask and the difficulty of the task itself, and theoretically motivated experiments are needed to more systematically investigate the possibility of increased masking in migraine, taking account of baseline performance. On the whole, there seems to be some indication that migraine groups might be more affected by some effects of masking.

\section{Global coherence}

Visual perception requires not only the effective detection of localised information, but also the integration of this information across space and time. The integration of information across space allows for the detection of coherent form, and is achieved through a combination of excitatory and inhibitory interactions between neurons with nearby receptive fields, forming 'association fields' (7675), as illustrated in Figure 3. Analogously, the integration of local information across time is needed for the successful detection of global motion (77잠). Successful performance on global motion and form tasks thus relies on successful global pooling processes. A summary of the literature on global form and motion tasks can be seen in Table 2.

\section{Global form perception}

The Glass pattern is a stimulus that has been developed to understand how local information is integrated to perceive shape (7778). Figure 4a shows an example consisting of randomly positioned pairs of dots. The orientation of the dot pair is orthogonal to its direction from the centre of the stimulus, so that the overall pattern appears to consist of a number of concentric circles. Similar Glass-line patterns can be created using lines rather than pairs of dots (Figure $4 \mathrm{~b}$ ). The global coherence of Glass patterns can be reduced by randomising the orientation of a proportion of the dot pairs or lines. Some studies have found poorer performance in migraine compared to control groups to detect global shape $(79 ; 8078,79)$. This impairment is also found in children with migraine (10-18years) but not in younger children (6-9years) (81무).

| However, this deficit appears to be task-dependent: (8281) used a different task, based on discrimination between two Glass patterns, rather than detection of a single Glass pattern, and found no difference for either condition between people with migraine and a control group. Similarly, other researchers $(71 \underline{70})$ found no difference in the magnitude of deviation from the circle that could be detected between people with migraine and a control group. Using a similar task, but with a continuous contour, higher thresholds for people with migraine with aura than for a control group and | those with migraine without aura were reported (754ㄱ). No difference was found between the latter two groups.

It appears that deficits are found in migraine when the stimulus consists of discrete | signal and noise elements $(79 ; 80 ; 81 \underline{78,79,80})$ but not when all elements contribute 
to the signal, but are corrupted by noise $(82,71 \underline{81,70)})$. This is theoretically interesting because it might indicate that there is not an issue with integration of elements per se, but that the increasing external noise from less coherent stimuli has a greater impact on migraine groups compared to controls for detection tasks. This pattern of results is reflected in the perception of global motion (see below) and | suggests an inability to exclude visual noise in migraine (8382).

\section{Motion coherence}

In global motion coherence tasks, observers are required to detect the direction of a signal motion (e.g. movement to the right) in a set of randomly positioned dots, in the presence of incoherent motion noise (Figure 4d-f). This task requires the integration of motion information across space and time, and is linked to extra-striate processing in cortical area V5/MT+ $(84,8583,84)$. Deficits in global motion processing in migraine have been shown in a number of studies $(85,86,78,79,61,59,86,87$, $80,79,87-88,2,8988,8281)$, and these may be related to anatomical differences, such as cortical thickening of V3A and $\mathrm{MT}+$, in the motion processing pathway (9089). Other researchers also found worse performance on a motion coherence task in a | group of children with migraine (9190). Differences in performance were particularly pronounced in the youngest age group ( 8 years old), and improved with age for the group with migraine, but not for the control group. The authors concluded that the development of visual motion processing is delayed in migraine, but normalises with time. However, since deficits in global motion tasks have been found in adults in other studies, these differences cannot be purely down to delayed development.

Tibber and colleagues measured sensitivity to global motion in two ways: by varying the proportion of signal to noise dots in a stimulus, as in other studies, and by disrupting the motion information conveyed by all dots (832). In the latter case, dots are not divided into distinct signal and noise groups. The direction of each dot is instead drawn from a Gaussian distribution. The observer's task is then to determine the mean direction of motion, and the difficulty of this task is varied by changing the standard deviation of the distribution. They found that performance was worse in migraine in the former case, but not the latter. They attributed this to a failure to exclude the motion information conveyed by the noise dots, rather than an increase in internal neural noise, which would have affected performance for both types of stimulus. It was found that motion coherence thresholds were higher in people with migraine, and that these covaried with differences in contrast sensitivity (89 $\underline{88}$ ). This is important as it could be the case that low-level visual deficits could account for the higher-level findings. Alternatively, the two deficits might have a common mechanism. In any case, the relationship between low and higher level deficits should be considered in research. An interesting finding of this study was that performance was slightly better in people with migraine at low levels of added dynamic noise. Dynamic noise involved a task-irrelevant stimulus in the background, in this case stationary, flickering noise dots in the random dot array. This difference was not found in the control group. This is an interesting finding, as it shows that adding taskirrelevant noise improved performance in migraine, when it is generally considered that adding a particular type of task-irrelevant stimuli would impair performance, for example in the case of masking. 


\section{Adaptation and aftereffects}

Viewing a stimulus for a period of time can lead to adaptation and habituation, resulting in after-effects. The processes underlying aftereffects can include neural | fatigue, and possibly gain control, and have been reviewed (9291).

\section{Tilt aftereffects}

After viewing a tilted stimulus for a period of time, other similar stimuli appear to be tilted in the opposite direction. These tilt aftereffects are generally increased in migraine, both for stimuli presented one after the other (9392) and also for stimuli presented simultaneously, alongside each other (9493). This is at first sight curious because, as previously discussed, sensitivity to differences in orientation is lower in migraine. Therefore it is plausible that the greater aftereffect is due to a less selective neural response in the first place, dete teas a result of less inhibition between neurons. This might then lead to a greater initial response and therefore a larger after-effect.

\section{Motion aftereffects}

After viewing a moving image for a prolonged period of time, there is a tendency for subsequently viewed stimuli to appear as though they are moving in the opposite | direction. Shepherd $(93,8892,87)$ showed that the duration of this motion aftereffect (MAE) is longer in migraine.

Battista and co-workers (9594) assessed the MAE and also used it to measure the effects of surround suppression, and showed reduced MAE only for large, high contrast stimuli in migraine. This is consistent with increased surround suppression: The strength of the aftereffect reduces for large stimuli, due to surround suppression of the response of motion detectors as the stimulus extends beyond their receptive field (9695).

\section{$\underline{\text { Palinopsia }}$}

Another form of aftereffect that is more common in migraine than controls is palinopsia. This refers to the persistence or recurrence of images once the stimulus has been removed (96). It can take many forms, which typically involve the persistent perception of objects, actions, parts of objects or textures, and the incorporation of these into the currently viewed scene. Palinopsia is more common in migraine than those without. It has been reported that palinopsia occurred in around $10 \%$ of people with migraine, and found no incidence of this condition in their sample of 226 healthy controls (97). Palinopsia was more common in patients with migraine with aura, than in those without aura. Patients with palinopsia tended to have less frequent migraine attacks. Like migraine, palinopsia has been associated with cortical hyperactivity and cortical spreading depression (96).

\section{Effects of adaptation on flicker detection and discrimination}


Elevated thresholds in migraine have been found for the detection and discrimination of changes in contrast to blurred spots or edges, after adaptation to $70 \mathrm{~Hz}$ and $10 \mathrm{~Hz}$

| flicker (2725). The authors suggested that this increased adaptation was due to either increased levels of neural fatigue, or a difference in gain control. A similar pattern of | results was found (9798), at a cortical level of processing, at which neurons respond to inputs from both eyes.

\section{Habituation and adaptation are different in migraine}

The fact that, on the whole, aftereffects are increased in migraine indicates differences in habituation and adaptation processes. A lack of habituation to stimuli might plausibly result in a longer-lasting response, and possibly even a build-up of the response, without time to return to baseline in between. However, these differences | are difficult to interpret as there are multiple explanations of aftereffects (e.g. 9291).

\section{Theoretical accounts of visual processing differences in migraine}

There are a number of differences in visual processing in migraine. Despite variation between individuals and studies, some broad generalisations can be made. Vision in migraine can be characterised as showing (i) reduced contrast sensitivity (ii) increased effects of adding noise to visual stimuli (iii) poorer global motion and form perception and (iv) stronger, longer-lived aftereffects.

A number of theoretical accounts of these differences have been proposed. Once such theory relates to evidence suggesting that the brains of people with migraine show greater levels of activity than others'. This has been termed 'hyperexcitability', but there is some variation in how this term is used. Coppola and colleagues use hyperexcitability specifically to mean a response to an external stimulus that is larger than that typically observed (9899). Other researchers (e.g. 8887) use a broader definition, to include both increased baseline activation and an increased response to visual stimulation. This variation in the use of terminology highlights the need for precisely specified theoretical models to understand visual processing. Here, we consider the way that these models have been developed in vision science, and how they may be applied to understand migraine.

\section{A General Signal Processing Model}

At a very general level, we can consider the activity of visual neurons to consist of a component that is informative about the input visual image, and a component that is not. This has been summarised mathematically in many papers, but a simple, general expression is given by:

$$
\mathbf{O}=\mathbf{K}(\mathbf{S})+\mathbf{N}_{\mathbf{a}}
$$

following Zhaoping (99100). Here, $\mathbf{O}$ is the output (response), $\boldsymbol{S}$ is the stimulus, $\mathbf{K}(\mathbf{)}$ the encoding function and $\mathbf{N}_{\mathbf{a}}$ the internal, spontaneous background noise (Figure 5). The noise term captures all neural activity that is independent of the input visual 
stimulus. According to this description, increased neural activity could arise in two ways. First, the encoding function $\mathbf{K}()$ might create a larger response for a given input, which will be referred to here as hyperresponsiveness. Second, the spontaneous background activity $\boldsymbol{N}_{\boldsymbol{a}}$, here referred to as stimulus-independent noise might be higher. In this case, although the level of activity has increased, the signal-to-noise ratio has been reduced.

The idea that the gain of the response $\mathbf{K}()$ may be varied in this model is crucial if the visual system is to make efficient use of its metabolic resources (100101). The optimal gain, or strength with which the visual system should respond to an input signal, depends on the signal-to-noise ratio. When this is high, the gain can be low, and adequate information about the signal will be transmitted. If the ratio of the signal to noise reduces, greater gain, or responsiveness, will be required to maintain information about the signal. The visual system thus needs to adapt the gain of its response to take account of changes in the strength of the input visual stimulus.

A further complication to the model outlined in Equation (1) is that it may also be necessary to consider multiplicative noise: that is, random variation in the response, the magnitude of which depends on the input stimulus (Figure 5). Adding a multiplicative noise $\left(\mathbf{N}_{\mathbf{m}}\right)$ term to (1) gives

$$
\mathbf{O}=\mathbf{K}(\mathbf{S})\left(1+\mathbf{N}_{\mathbf{M}}\right)+\mathbf{N}_{\mathrm{a}}
$$

The important distinction here is that multiplicative noise refers to an increase in activity in response to an input stimulus, but one that does not provide any information about the nature of the stimulus. It is important to note however that, despite the theoretical difference, there is no way of discriminating between multiplicative noise and a combination of gain control and late additive noise from psychophysical experiments, as their predictions are mathematically equivalent (676ㅡ).

Henceforth, hyperexcitation will be used to describe either of these possibilities; the more specific terms will be used wherever possible. As we shall see, this distinction is critical to understanding the results of physiological and psychophysical data.

\section{Accounting for visual processing differences in migraine}

With this very general theoretical framework in place, we can now consider some of the explanations of sensory processing differences, and how they relate to the components outlined in the previous section. It has been proposed that the cortex is hyperresponsive (9899) or hyperexcitable (101102) in migraine, and also that it is associated with a reduction in neural inhibition (e.g. 7271) or habituation (102103). Each of these ideas, in turn, may be related to the model of visual encoding outlined above, as well as to subsequent processing of the encoded information.

Hyperresponsiveness: This is the idea that the brain responds more strongly to sensory stimuli in migraine. This would be represented by an increase in the gain of the function $\mathbf{K}()$. However, as noted previously, in conjunction with differences in additive noise, this is mathematically equivalent to increased multiplicative noise 
$\left(\mathbf{N}_{\mathbf{m}}\right)$, and therefore it is difficult to derive theory and experiment to discriminate the two (e.g. 67 $\underline{66}$ ).

Hyperexcitability: Increased neural activity in migraine need not necessarily result from an increase in responsiveness to sensory stimuli. Thus, while activity may be higher overall, this might arise not from an increase in sensitivity to visual stimulation $\mathbf{K}$ ), but from an increase in the background level of activity $\left(\mathbf{N}_{\mathbf{a}}\right)$, or stimulus-induced noise $\left(\mathbf{N}_{\mathbf{m}}\right)$.

Reduced inhibition: Many aspects of visual processing depend on both excitatory and inhibitory interactions between neurons. It has been proposed that inhibitory | interactions between neurons are reduced in migraine (103104). This would manifest itself as increased $\mathbf{N}_{\mathbf{m}}$, as the lack of inhibitory connections would necessarily result in stimulus-dependent noise. Reduced inhibition might also affect the successful operation of the association fields required for the detection of coherent form in visual stimuli (7675).

Reduced habituation: If a visual stimulus is repeatedly presented to an observer, the visually evoked potential tends to decrease. This process of habituation is less | pronounced in migraine $(104 \underline{105})$. The temporal dynamics of visual processing are not modelled by Equation (2), but this could be extended to allow its parameters to change over time. In such a model, a difference in habituation would then reflect differences in the way that the gain function $\mathbf{K}($ ), changes over time.

\section{Application of signal processing models of vision to migraine}

| The ideas outlined in section-above provide a very general way of considering the neural processing of visual signals. A variety of conceptually very similar models are used in vision science, $(105 \underline{106})$, and some researchers have applied them to migraine $(70,7569,74)$. Wagner and colleagues concluded that increased masking effects in migraine were due to increased multiplicative noise (709) ), whilst in later years claimed that poorer performance to discriminate a masked shape was due to differences in gain control in the migraine group (7574). Mathematically, the two formulations make identical predictions for the types of psychophysical data modelled. This highlights the difficulty, if not impossibility, of determining the single correct model to account for performance, even when physiological evidence is taken into account $(106,107,108,109,110107,108,109,110,111)$. In addition, the template of the Lu and Dosher model is task-specific, and therefore would take a different form depending on what the observer was doing. For these reasons, Equation (2) is used merely to show the effects that putative differences in visual processing would have in migraine. This is not presented as the single correct model that should be used, but as a simple, generalised formulation. For example, the model here is restricted to interictal visual function. This could be achieved for example if the parameters of the model varied across the migraine cycle. Additionally, this is a model of visual processing, however a similar principle might plausibly apply to other sensory modalities.

Theoretical explanations of visual processing differences in migraine

\section{Reduced contrast sensitivity}


The ability to detect a stimulus relies on the sensitivity of the system, but the signal must also be strong enough to overcome the level of noise intrinsic to the system (111112). Reduced sensitivity, or responsiveness, of the system, indicated by the encoding function $\mathbf{K}()$ would decrease the signal strength. This would appear unlikely in migraine as evidence suggests the visual system is more, not less, sensitive compared to controls. However, contrast sensitivity is determined by the level of internal noise, as well as the responsiveness to the signal. A possible explanation for reduced contrast sensitivity would be any increase in either the additive $\left(\mathbf{N}_{\mathbf{a}}\right)$ or multiplicative $\left(\mathbf{N}_{\mathbf{m}}\right)$ component of internal noise in the visual system, but additional tests of visual performance would be needed to discriminate which. Note also that the issues of the responsiveness and noisiness of neural activity are not independent. Ideally, an efficient encoding of sensory information needs to include gain control, such that responsiveness is lower when signal-to-noise ratios are high, so as not to waste resources on encoding an already strong signal, and higher when signal-tonoise ratios are low, in order to raise the signal above the level of the noise (99100). Thus, an increase in noise could be a direct cause of the increased neural activity recorded, while nevertheless still resulting in a reduction in contrast sensitivity. This

argument has been put forward (101102), and is a compelling theoretical explanation of why reduced contrast sensitivity might be observed in a hyperresponsive system.

\section{Increased effects of externally added noise}

As previously mentioned, adding noise to a stimulus is in general expected to make performance worse. There is however more than one way of adding external noise to a stimulus, and of how this then affects visual processing (696ㅛ).

Two studies have found that contrast detection thresholds for small targets are no different in migraine when presented in isolation, but worse in the presence of an externally added noise mask $(70 ; 71 \underline{69,70})$. Following Lu and Dosher's noisy perceptual template model (105), these results were interpreted either as showing

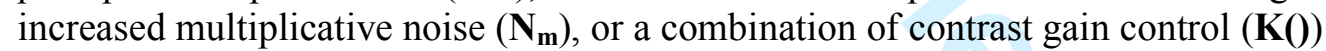
and a further source of additive noise $\left(\mathbf{N}_{\mathbf{a}}\right)$. Recent work (6968) pointed out that in typical masking paradigms, as used previously $(70,71 \underline{69,70})$, the noise component of the stimulus will produce large responses in mechanisms other than that used to detect the signal, such as suppressive interactions. Thus, rather than masking reflecting the response of the signal-detecting mechanism to the noise, it could reflect the activity induced in these other mechanisms. This is particularly relevant given the argument that the difficulty in migraine is primarily that of an in ability to selectively ignore irrelevant stimuli (832ㅡ).

\section{Poorer global pooling}

Poorer performance on global form and motion tasks could be accounted for in terms of decreased gain $(\mathbf{K}())$, increased additive noise $\left(\mathbf{N}_{\mathbf{a}}\right)$ or a reduced ability to ignore external noise $\left(\mathbf{N}_{\mathbf{a}}\right.$ or $\left.\mathbf{N}_{\mathbf{m}}\right)$. Recent work (832ㅡ) suggests that, in fact, internal noise measured using equivalent noise paradigms is not increased in migraine, but that poorer motion coherence thresholds can be related to an inability to ignore the 
additional external noise added to the stimulus. Although noise is generally detrimental for performance, this is not always the case. Sometimes adding a small amount of noise can improve performance, known as stochastic resonance. It has been shown that In addition, (112) showed that, somewhat counter-intuitively adding a small amount of noise to Glass patterns, in the form of additional elements incoherent with the pattern, can increase performance on a task to detect the overall shape (113). This result was found in non-clinical populations, however, the principle also applies to migraine groups., Glass patterns have a more stable structure when noise is added in normal populations. There has been some indication of is also the possibility of stochastic resonance in migraine populations in a global motion task (e.g. 89 $\underline{88}$ ). Adding a small amount of noise in the form of 'twinkling' background dots, not moving coherently with the signal dots, improved performance in the migraine group. which would mean that a small amount of external noise would inmprove performance. Although it is unclear whether or not theis phenomenon of stochastic resonance occurs in the brain, it is important to bear in mind for theoretical reasons, particularly given that people with migraine have been reported to benefit from low levels of external noise in cases where control participants do not (89 $\underline{88}$ ). All these reasons further highlight the importance of careful consideration of the processes involved when adding external noise to a stimulus.

However, any differences in the inhibitory and excitatory connections that comprise the local association fields would also be expected to compromise performance on global form and motion tasks. Additionally, a specific deficit for global tasks might be the result of increased noise at a later stage of processing from the detection level, of a form that is not captured by Equation 2.

\section{Increased strength and duration of aftereffects}

Aftereffects need to be considered as a multistage process. Firstly, there is the adaptation phase, where cells habituate to the constant stimulation, and secondly, the 'test' phase, when the aftereffect is experienced. If there is reduced habituation in the adaptation phase, this would result in reduced aftereffects in the test phase. If inhibition is reduced in the adaptation phase, then this might predict an impoverished adapting stimulus, as there will be reduced selectivity and therefore more noise. An increase in the magnitude and duration of the MAE is unlikely to result from a heightened response to the adapting visual stimulation, since neither of these effects | result from an increase in the physical contrast of the adaptor (113 114).

During the test phase, an increased aftereffect could result from reduced dishabituation to the stimulus (114115). Shepherd has argued that the differences between migraine and control groups can best be explained by a slower recovery in | migraine resulting in extended suppression of excitatory connections (8887). This is consistent with increased effects of externally added noise.

\section{Summary}

An increase in neural noise, either increased background noise $\left(\mathbf{N}_{\mathbf{a}}\right)$ or multiplicative noise in response to a stimulus $\left(\mathbf{N}_{\mathbf{m}}\right)$, provides a natural explanation for the 
hyperresponsiveness found interictally in migraine. The visual system needs to maintain optimal gain control, in order to make efficient use of metabolic resources. An increase in the gain on incoming signals would ameliorate the reduction in signalto-noise ratios caused by higher additive noise levels $\left(\mathbf{N}_{\mathbf{a}}\right)$. Since this increase in gain will come at a metabolic cost, it may not fully compensate for increased noise levels. Thus, increased gain in the presence of increased noise can account for the presence of overly large responses despite reduced performance on sensitivity tests.

The increased additive noise $\left(\mathbf{N}_{\mathbf{a}}\right)$ plus increased gain explanation does not directly account for the results of those studies that have added external noise to a stimulus; these include masking, surround suppression, global form and global motion tasks. The increased masking, increased surround suppression, and poorer global form and motion tasks, as well as reduced specificity in orientation discrimination, could be accounted for by an increased in multiplicative noise $\left(\mathbf{N}_{\mathbf{m}}\right)$, and are likely to represent differences in the excitatory and inhibitory interactions between neurons or groups of neurons. Increased multiplicative noise has already been applied to explain the | impairment in global motion and form coherence (e.g. 7069). However, either the Na plus gain control $(\mathbf{K}())$ or the multiplicative noise explanations $\left(\mathbf{N}_{\mathbf{m}}\right)$ are mathematically, and behaviourally, very similar, and so designing studies to discriminate between the two is difficult. This can be seen in that the first paper (7069) applies one explanation, and the second paper (7574) applies the other to explain coherence deficits in migraine. However, in conclusion, the psychophysical results can be accounted for by increased effects of internal noise in migraine.

$\underline{\text { The focus of this review is on vision, however, there are other sensory modalities that }}$ are important in migraine. For example, as well as photophobia, phonophobia (increased sensitivity to sound) and osmophobia (increased sensitivity to odours) are also symptoms of migraine attack (1). Analogously to visual stimulation, exposure to sound can cause discomfort (116). As well as analogous sensory modalities, there is also evidence of multisensory processing differences in migraine (117). It has been argued that lowered pain thresholds in migraine are accompanied by lowered thresholds to light, sound, and olfactory stimulation and there is also greater integration of information from different sensory modalities, and greater functional connectivity in migraine (117). Greater functional connectivity could lead to increased noise if other brain regions are being recruited that are not directly involved with the task. Multisensory processing can be measured using the McGurk effect, or the flash-beep illusion, which rely on the integration of visual and auditory inputs. On a mechanistic level, the integration period of the flashbeep illusion in non-clinical populations is related to the frequency of alpha band $(8-14 \mathrm{~Hz})$ neural oscillations over the visual cortex. These are ongoing rhythms of the visual cortex, thought to be the readiness state of the visual areas of the brain, and involved in controlling perception (118), termed a 'window of excitability' (119). As there is some evidence of a possibility to train alpha band oscillations $(120,121)$, it might be the case that there is a potential future therapy in terms of driving these oscillations to vary the extent to which multisensory information is integrated. This is rather speculative and would need direct testing in migraine. However, there is recent evidence of increased visual/auditory integration in migraine groups (122). 
As well as sensory information, the principle of overintegration might also include the vestibular system. Some types of migraine are associated with vertigo, and postural imbalances (123). Vertigo is a feeling of dizziness, associated with increased nystagmus, both spontaneous (in any position) and positional (when the orientation of the individual's head is changed). It has been shown that while watching a 'rotating snake' illusion, which causes the perception of illusory motion in a static image, individuals with migraine showed less postural stability than controls (124). However, when a break was given after viewing the illusion and then measuring postural stability, the authors found no group differences. Thus they concluded that the effect of the illusory motion on postural sway in migraineurs must be related to the motion after-effect caused by viewing the stimulus. A link between migraine vertigo and the trigemineal system has been shown: More individuals with migraine showed spontaneous nystagmus than controls (125). This number increased in the migraine group on stimulating the trigemineal system, which was not seen in controls. As nystagmus is related to vertigo, this suggests a link between the integration of visual and vestibular information in migraine.

The origin of the noise is an important outstanding question, however, a thorough account of all possible mechanisms is beyond the scope of this review. To speculate over some of the potential mechanisms, over-recruitment of different areas of the brain is one possible source of noise. Reduced inhibition is one potential source of noise, and can result in a reduced ability to ignore noise in tasks such as global motion eoherence Alternatively, there is evidence of genetic malfunctions relating to disturbances in ion channels that also might plausibly be a source of noise. Mice with CACNA1A gene mutation are found to show the same clinical symptoms as familial hemiplegic migraine (126). Mutated mice showed increased $\mathrm{Ca}^{2+}$ current density, more glutamate release at excitatory cells, and greater susceptibility to cortical spreading depression, but no differences in GABA controlled, inhibitory interneurons (127). The mutated mice also showed increased spontaneous activation, which might be a potential source of noise in the response to stimuli. Research has shown that the mutation on the CACNA1A gene is important in terms of migraine as this gene encodes the $\mathrm{P} / \mathrm{Q}$ voltage-gated $\mathrm{Ca}^{2+}$ channels (128). It has long been noted that blocking calcium channels using drugs is helpful in both common and classic migraine (129). Pietrobon (130) argued that as $\mathrm{P} / \mathrm{Q} \mathrm{Ca}^{2+}$ channels act as a gatekeeper for excitatory $\mathrm{K}+$ channels, this relates to the gain function of the cell. It has been shown that mice with a mutated CACNA1A, resulting in $\mathrm{P} / \mathrm{Q} \mathrm{Ca}{ }^{2+}$ channel differences, showed more irregular Purkinje cell firing rates (131). This irregularity in firing rate was both with and without stimulation. Speculatively, it might be plausible that more irregular firing could be the cause of noisier signal transmission. Although this is indirect, in the fly visual system, voltage dependent gates are related to the gain control of a visual signal (132). $\mathrm{P} / \mathrm{Q} \mathrm{Ca}{ }^{2+}$ channels are also associated with the increased sensitisation of the trigemineal nucleus (130). Voltage-gated $\mathrm{P} / \mathrm{Q} \mathrm{Ca}^{2+}$ channels are also responsible for the transmission of pain, and pain is reduced when this channel is blocked (133). Although research using animal models is mostly limited to familial hemiplegic migraine, it is thought that this and migraine with aura are part of the same spectrum of disorder (134). Therefore, there might be, in principle, genetic abnormalities leading to $\mathrm{Ca} 2+$ ion channel differences and thus irregular neural firing. This might represent a possible source of noise, and a possible area for future research. However, it must be emphasised that all of this is speculative for the time being. 
Although GABA-controlled inhibition on a neural level seems unaffected, at least for a subtype of migraine, over-recruitment of different areas of the brain could be due to reduced inhibition between brain areas. - Inhibition is a term that has multiple meanings, depending on the scale of the processes involved. For example, there is inhibition between adjacent cells, or groups of cells, responding to different features in the early areas of the visual cortex. There are also more long range inhibitory processes, involving the suppression of alternative representations, which might be needed in the case of visual search tasks, to enable the viewer to ignore distracters $(115135)$. There are inhibitory processes that rely on timing, as is thought to be the case in some after-effects. It is not helpful to be indiscriminate in the use of the term | 'inhibition', and theory would benefit from clearly defining the term in context.

The effects of moving stimuli might be particularly relevant, as these are stimuli that are temporally modulated. Studies using prolonged presentations have shown on the whole that the aftereffects last longer in migraine. Aftereffects could be a measure of the ability to adapt to a stimulus, and habituate the response, and it is unclear exactly which processes are involved in an aftereffect (9291), therefore more theoretically motivated experiments need to be designed before this can be assessed. It is possible that the time course of neural activity is actually the critical factor in migraine visual performance. For example, differences have been found in habituation in migraine for stimuli presented at $3 \mathrm{~Hz}$ only, not at other presentation rates (116136). The association with flicker is common in migraine, and needs to be considered in the research. This is not accounted for by the model in its current form, and therefore this will need to be expanded to include the dimension of time.

As well as short term temporal effects, it is also important to consider the model in terms of the progression of the disease. It has been shown that attack frequency, and duration of the disorder, both associate with more damage to white matter in the brain (137). Although there has been some debate over whether migraine causes damage to the brain, a meta-analysis suggests that overall, migraine is associated with increased white matter lesions (138). Whether the lesions occur due to migraine attacks, or are a cause of the attacks, is as yet unclear. This is of importance to sensory processing as white matter lesions are also found in children with sensory disorder (139), and could therefore be related to poorer visual performance in migraine. White matter lesions in older adults were associated with both increased functional connectivity, and poorer performance on a visual task (140). This could be a possible cause of increased noise in the brain. Although this has been demonstrated in a non-clinical population of older adults, this is not necessarily applicable to migraine, and so the argument remains speculative.

One possible therapy that is relevant to noise is tinted filters. These have been demonstrated to be of benefit in migraine (141). (21) demonstrated a possible mechanism for this in terms of a reduction in fMRI BOLD response to stimuli when viewed through tints. The tints are specific to the individual with migraine in order to have any benefit. Although the mechanism for this is unclear, one might speculate that increasing the specificity of the response would help with increased noise/reduced gain. 


\section{Conclusion}

Migraine is a common and debilitating neurological disorder. There are many associations between migraine and vision, including visual triggers of attacks, visual auras and differences in performance on visual tasks compared to control groups. Importantly, there are a number of low-level differences that suggest fundamental differences in sensory processing in migraine. These can be summarised as (i) reduced contrast sensitivity (ii) reduced sensitivity to differences in orientation (iii) increased effects of adding noise to stimuli (iv) poorer perception of global motion and form and (v) stronger, longer-lived aftereffects.

A number of theoretical accounts of these differences have been proposed in the literature. One difficulty with comparing these has been some degree of variation in the way that terminology is used, and a lack of precise definition of this terminology (98). Overall, differences in migraine could be accounted for by increased effects of noise, and/or differences in excitatory and inhibitory processes. Increased clarity at the level of theoretical accounts of sensory processing differences is important in driving novel empirical work, with a view to a better understanding of the disorder and the development of novel treatments.

\section{Article Highlights}

Migraine is a common disorder, associated with visual processing differences. The review focusses on behavioural studies of visual processing in migraine. Migraine groups show reduced sensitivity to contrast, and orientation, and difficulty processing moving stimuli.

Suggested theories include hyperexcitation, or an inability to exclude noise. An established mathematically-defined signal-processing model is applied, to clarify terminology and highlights future research and treatment implications.

\section{References}

1 Headache classification committee of the International Headache Society (HIS). Classification and diagnostic criteria for headache disorders, cranial neuralgias and facial pain. Cephalalgia, 2013; 33(9): 629-808.

2 Debney, L.M. Visual stimuli as migraine trigger factors. In: Rose, F. C., (ed) Progress in migraine research. London, UK: Pitman Books, 1984.

3 Kelman, L. The triggers or precipitants of the acute migraine attack. Cephalalgia, 2007; 27(5): 394-402.

4 Shepherd, A. J. Visual contrast processing in migraine. Cephalalgia, 2000; 20(10): 865-880.

5 Lipton, R. B., Diamond, S., Reed, M., et al. Migraine diagnosis and treatment: Results from the American Migraine Study II. Headache, 2001; 41(7): 638-645. 
6 Steiner, T. J., Scher, A. I., Stewart, W. F., et al. The prevalence and disability burden of adult migraine in England and their relationships to age, gender and ethnicity. Cephalalgia, 2003; 23(7): 519-527.

7 Sacks, O. Migraine. London: Faber and Faber, 1992.

8 Schott, G. D. Exploring the visual hallucinations of migraine art: The tacit contribution of illustration. Brain, 2007; 130(6): 1690-1703.

9 Lashley, K. S. Patterns of cerebral integration indicated by the scotomas of migraine. Archives of Neurology and Psychiatry, 1941; 46(2): 331-339.

| 103 Hay, K. M., Mortimet, M. J., Barker, D. C. et al. 1044 women with migraine: the effect of environmental stimuli. Headache, 1994; 34: 166-168

| 114 Vanagaite, J., Pareja, J. A., Støren, O., White, L. R., Sanc, T., Stovner, L. J., (1997). Light-induced visual discomfort and pain in migraine. Cephalalgia, 17(7), 733-741.

125 Main, A., Vlachonikolis, I., and Dowson, A. The wavelength of light causing photophobia in migraine and tension-type headache between attacks.

Headache, 1997; 40(3):194-199.

16-13 Okamoto, K., Tashiro, A., Chang, Z., et al. Bright light activates a trigeminal nocioceptive pathway. Pain, 2005; 149(2): 235-242.

| 1714 Drummond, P. D. Photophobia and autonomic responses to facial pain in migraine. Brain, 1997; 120: 1857-1864.

| 18-15 Drummond, P. D., and Granston, A. Facial pain increases nausea and headache during motion sickness in migraine sufferers. Brain, 2004; 127: 526-534.

19-16 Drummond, P. D., and Woodhouse, A. Painful stimulation of the forehead increases photophobia in migraine sufferers. Cephalalgia, 1993; 13: 321-4.

| 2017 Noseda, R., Kainz, V., Jakubowski, M., et al. A neural mechanism for exacerbation of headache by light, Nature Neuroscience, 2010; 13:239-246.

| 21-18 Boulloche, N., Denuelle, M., Payoux, P., et al. Photophobia in migraine: An interictal PET study of cortical hyperexcitability and its modulation by pain. Journal of Neurology, 2010; 81(9): 978-84.

| 1922 Marcus, D. A., and Soso, M. J. Migraine and stripe-induced visual discomfort. Archives of Neurology, 1989; 46(10):1129-1132.

23-20 Harle, D.E., Shepherd, A.J., and Evans, B.J.W. Visual stimuli are common triggers of migraine and are associated with pattern glare. Headache, 2006; 46: 14311440 . 
24-21 Huang, J., Zong, X., Wilkins, A. J., et al. fMRI evidence that precision ophthalmic tints reduce cortical hyperactivation in migraine. Cephalalgia, 2011; 31(8): 1-12.

25-22 Haigh, S. M., Karanovic, O., Wilkinson, F., et al. Cortical hyperexcitability in migraine and aversion to patterns. Cephalalgia, 2012; 32(3):236-40.

26-23 Wilkinson, F., Karanovic, O., and Wilson, H. R. Binocular rivalry in migraine. Cephalalgia, 2008; 28(12): 1327-38

| 27 24 Karanovic, O., Thabet, M., Wilson, H. R., and Wilkinson, F. Detection and discrimination of flicker contrast in migraine. Cephalalgia, 2011; 31(6): 723-736.

| 28-25 De Tomasso, M., Ambrosini, A., Brighina, F., et al. Altered sensory processing stimuli in patients with migraine. Nature Reviews Neuroscience. 2014; 10(3): 144-55.

11 Jürgens, T.P., Schulte, L.H. \& May, A.M. Migraine trait symptoms in migraine with and without aura, Neurology, 2014; 82: 14161424.

12 Hougard, A., Amin, F., Hauge, A. W., et al. Provocation of migraine with aura using natural trigger factors. Newrology, 2013; 80: 428431.

$28-26$ Khalil, N.M. Investigations of visual function in migraine using visual evoked potentials and psychophysical tests. PhD thesis, University of London, 1991.

29-27 McKendrick, A. M., and Sampson, G. P. Low spatial frequency contrast sensitivity deficits in migraine are not visual pathway selective. Cephalalgia, 2009; 29(5): 539-549.

| 30-28 Coppola, G., Parisi, V., di Lorenzo, C., et al. Lateral inhibition in visual cortex of migraine patients between attacks. The Journal of Headache and Pain, 2013; 14: 120 .

| 31-29 Siniatchkin, M., Averkina, N., Andrasik, F., et al. Neurophysiological reactivity before a migraine attack. Neuroscience Letters, 2006; 400(1-2): 121-124.

| 3230 Sand, T., Zhitniy, N., White, L. R., et al. Visual evoked potential latency, amplitude and habituation in migraine: A longitudinal study. Clinical Neurophysiology, 2008; 119: 1020-1027.

| 3133 Sand, T., White, L. R., Hagen, K., et al. Visual evoked potential and spatial frequency in migraine: A longitudinal study. Acta Neurol Scand, 2009; 120(S189): 33-37.

| 34 32 Judit, Á., Sándor, P.S. \& Schoenen, J. Habituation of visual and intensity dependence of auditory evoked cortical potentials tend to normalize just before and during the migraine attack, Cephalalgia, 2000; 20: 714-719. 
35-33 Evers, S., Quibeldey, F., Grotemeyer, K. H., et al. Dynamic changes of cognitive habituation and serotonin metabolism during the migraine interval. Cephalalgia, 1999; 19(5): 485-491.

| 36-34 Shibata, K., Osawa, M., and Iwata, M. Pattern reversal visual evoked potentials in migraine with aura and migraine aura without headache. Cephalalagia, 1998; 18(6): 319-23.

37 35 Nguyen, B. N., Vingrys, A. J., and McKendrick, A. M. The effect of duration post-migraine on visual electrophysiology and visual field performance in people with migraine. Cephalalgia, 2014; 34(1): 42-57.

| 38-36 DeMarinis, M., Rinalduzzi, S. \& Accornero, N. Impairment in color perception in migraine with and without aura. Headache, 2007; 47: 895-904.

| 39-37 Shepherd, A. J. Colour vision in migraine: selective deficits for S-cone discriminations. Cephalalgia, 2005; 25(6): 412-423.

10 38 Shepherd, A.J. Color vision but not visual attention is altered in migraine. Headache, 2006a; 46: 611-621.

41 39 Tibber, M. S., and Shepherd, A. J. Transient tritanopia in migraine: Evidence for a large-field abnormality in blue-yellow opponent pathway. Investigative Ophthalmology and Visual Science, 2006; 47(11): 5125-5131.

| 4240 Harle, D. E., and Evans, B. J. W. Subtle binocular vision abnormalities in migraine. Ophthalmological and Physiological Optics, 2006; 26(6):587-596.

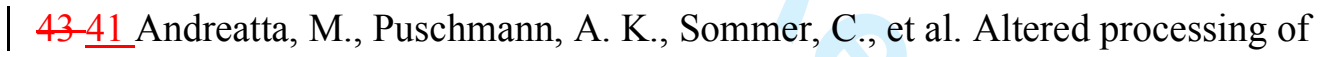
emotional stimuli in migraine: An event-related potential study. Cephalalgia, 2012; 32(15): 1101-8.

| $44 \underline{42}$ Shepherd, A. J., Hine, T. J., and Beaumont, H. M. Color and spatial frequency are related to visual pattern sensitivity in migraine. Headache, 2013; 53(7): 10871103.

| $45 \underline{43}$ Tibber, M.S., Guedes, A. and Shepherd, A.J. Orientation discrimination and contrast detection thresholds in migraine for cardinal and oblique angles. Investigative Ophthalmology and Visual Science, 2006; 47: 5599-5604.

| 4644 McColl, S. L., and Wilkinson, F. Visual contrast gain control in migraine: Measures of visual cortical excitibility and inhibition. Cephalalgia, 2000; 20(2): 7484.

$47 \underline{45}$ Yenice, Ö., Onal, S., Incil, B., et al. Assessment of spatial-contrast function and short-wavelength sensitivity deficits in patients with migraine. Eye, 2007; 21: 218223.

| $48 \underline{46}$ Mendes, L. C., Galdino, M. K. C., Vieira, J. G. Evaluation of contrast sensitivity among patients with migraine. Psicologia, 2011; 22(1): 81-97. 
4947 Benedek, K., Tajti, J., Janáky, M., et al. Spatial contrast

sensitivity of migraine patients without aura. Cephalalgia, 2001; 22(2): 142-145.

| $50 \underline{48}$ Khalil, N. M., Nicotra, A., and Wilkins, A. J. Asymmetry of visual function in migraine with aura: Correlation with lateralisation of headache and aura.

Cephalalgia, 2011; 31(2): 213-221.

5149 Braunitzer, G., Roskin, A., Kóbor, J., et al. Is the development of visual contrast sensitivity impaired in children with migraine? An exploratory study. Cephalalgia, 2010; 30(8): 991-995.

| 5250 Sato, H., Katsuyama, N., Tamure, H et al. Mechanisms underlying orientation selectivity of neurons in the primary visual cortex of the macaque. Journal of Physiology, 1996; 494(3):757-771.

| 53-51 Shapley, R., Hawken, M., Ringach, D. L. Dynamics of orientation selectivity in the primary visual cortex and the importance of cortical inhibition. Neuron, 2003; 38(5):689-99.

| 54 $\underline{52 E d d e n, ~ R . ~ A ., ~ M u t h u k u m a r a s w a m y, ~ S . ~ D ., ~ F r e e m a n, ~ T . ~ C ., ~ e t ~ a l . ~ O r i e n t a t i o n ~}$ discrimination performance is predicted by GABA concentration and gamma oscillation frequency in human primary visual cortex. The Journal of Neuroscience, 2009; 29(50): 15721-6.

| 55-53 Heeger, D. J. Normalization of cell responses in cat striate cortex. Visual Neuroscience, 1992; 9: 181-197.

| 56-54 Polat, U., and Sagi, D. Lateral interactions between spatial channels: Suppression and facilitation revealed by lateral masking experiments. Vision Research, 1993; 33(7): 993-999.

| $57 \underline{55}$ Nothdurft, H.C., Gallant, J.L., and Van Essen, D.C. Response profiles to texture border patterns in area V1. Visual Neuroscience, 2000; 17: 421-436.

58 56 Zhaoping, L., and May, K. A. Psychophysical tests of the hypothesis of a bottom-up saliency map in primary visual cortex. PLoS Computational Biology, 2007; 3(4): e62..

| 59-57 Kourtzi, Z., Tolias, A. S., Altmann, M. A., et al. Integration of local features into global shapes: Monkey and human fMRI studies. Neuron, 2003; 37: 333-346.

| 60-58 Wilkinson, F., and Crotogino, J. Orientation discrimination thresholds in migraine: A measure of visual cortical inhibition. Cephalalgia, 2000; 20(1): 57-66.

61 59 McKendrick, A. M., Vingrys, A. J., Badcock, D. R., et al. Visual dysfunction between migraine events. Investigative Ophthalmology and Visual Science, 2001; 42(3), 626-633. 
62 60 Battista, J., Badcock, D. R., and McKendrick, A. M. Migraine increases centre surround suppression for drifting visual stimuli. Investigative Ophthalmology and Visual Science, 2011; 6(4): e18211.

63-61 Chubb, C., Sperling, G. and Solomon, J.A. Texture interactions determine perceived contrast. Proceedings of the National Academy of Sciences of the USA, 1989; 86: 9631-9635.

| 63-62 Wray, S. H., Mijovic, D., and Kosslyn, S. M. Visual processing in migraineurs. Brain, 1995; 118: 25-35.

64-63 Palmer, J. E., and Chronicle, E. P.Cognitive processing in migraine: A failure to find facilitation in patients with aura. Cephalalgia, 1998; 18(3): 125-132.

6465 Conlon, E. G., and Hine, T. The influence of pattern interference on performance in migraine and visual discomfort groups. Cephalalgia, 2002; 20(8):708713.

| 66-65 Conlon, E. G., and Humphreys, L. Visual search in migraine and visual discomfort groups. Vision Research, 2001; 41(23): 3063-3068.

6766 Dao, D. Y., Lu, Z. L., and Dosher, B. A. Adaptation to sine wave gratings reduces the sensory gain of the adapted stimulus. Journal of Vision, 2006; 6(7): 739759 .

68 67 Webb, B.S. Dhruv, N.T., Solomon, S.G., et al. Early and late mechanisms of surround suppression in the striate cortex of the macaque. Journal of Neuroscience, 2005; 25: 11666-11675.

69-68 Baker, D. H., and Meese, T. S. Zero-dimensional noise: The best mask you never saw. Journal of Vision, 2012; 12(10): 1-12.

70-69 Wagner, D., Manahilov, V., Loffler, G., et al. Visual noise selectively degrades vision in migraine. Investigative Ophthalmology and Visual Science, 2010; 51(4): 2294-2299.

| 71 70 Webster, K.E., Dickinson, J.E., Battista, J., et al. Evidence for increased internal noise in migraineurs for contrast and shape processing. Cephalalgia, 2012; 32(2): $125-139$.

| 7271 Palmer, J. E., Chronicle, E. P., Rolan, P., et al. Cortical hyperexcitability is cortical under-inhibition: Evidence from a novel functional test of migraine patients. Cephalalgia, 2000; 20(6): 525-32.

| 73-72 Shepherd, A.J., Wyatt \& Tibber M.S. Visual metacontrast masking in migraine, Cephalalgia, 2011; 31: 346-356.

| 74 73 Huang, J., DeLano, M., and Cao, Y. Visual cortical inhibitory function in migraine 
is not generally impaired: Evidence from a combined psychophysical test with an fMRI study. Cephalalgia, 2006; 26(5): 554-560.

| 75-74 Wagner, D., Manahilov, V., Gordon, G. E., et al. Global shape processing deficits are amplified by temporal masking in migraine. Investigative Ophthalmology and Visual Science, 2013; 54(2): 1160-8.

| 76-75 Field, D. J., Hayes, A., and Hess, R. F. Contour integration by the human visual system: Evidence for a local "association field". Vision Research, 1993; 33(2): 173193.

| 77 76 Born, R. T., and Tootell, R. B. H. Segregation of global and local motion processing in rimate middle temporal visual area. Nature, 1992; 357: 497-499.

| 78-77 Glass, L. Moire effects from random dots. Nature, 1969; 223: 578-580.

| 79-78 Ditchfield, J. A., McKendrick, A. M., and Badcock, D. R. Processing of global motion and form in migraineurs. Vision Research, 2006; 46(1-2): 141-148.

80-79 McKendrick, A. M., Badcock, D. R., and Gurgone, M. Vernier acuity is normal in migraine, whereas global form and motion perception are not. Investigative Ophthalmology and Visual Science, 2006; 47(7): 3213-9.

81 $\underline{80}$ Braunitzer, G., Roskin, A., Kóbor, J., et al. Development of visual contour integration in children with migraine without aura. Cephalalgia, 2011; 31(9): 1048-56.

| $82 \underline{81}$ Webster, K.E., Dickinson, J.E., Battista, J., et al. Increased internal noise cannot account for motion coherence processing deficits in migraine. Cephalalgia, 2011; 31(11): 1199-1210.

83-82 Tibber, M. S., Kelly, M., Jansari, A., et al. An inability to exclude visual noise in migraine. Investigative Ophthalmology and Visual Science, 2014; 55(4): 2539-46.

84 $\underline{83}$ Rees, G., Friston, K., and Koch, C. A direct quantitative relationship between the functional properties of human and macaque V5. Nature Neuroscience, 2000; 3(7): 716-723

| 85-84 Braddick, O. J., O’Brien, J. M. D., Wattam-Bell, J., et al. Brain areas sensitive to visual motion. Perception, 2001; 30(1): 61-72.

| 86-85 Antal, A., Temme, J., Nitsche, M. A., et al., Altered motion perception in migraineurs: Evidence for interictal cortical hyperexcitability. Cephalalgia, 2005; 25(10): 788-794.

87 $\underline{86}$ McKendrick, A. M., and Badcock, D. R. Motion processing deficits in migraine. Cephalalgia, 2004; 24(5): 363-372.

88 87 Shepherd, A. J. Local and global motion after-effects are both enhanced in migraine, and the underlying mechanisms differ across cortical areas. Brain, 2006b; 129(7): 1833-1843. 
89-88 Shepherd, A. J., Beaumont, H. M., and Hine, T. J. Motion processing deficits in migraine are related to contrast sensitivity. Cephalalgia, 2012; 32(7): 554-570.

90-89 Granziera, C., DaSilva, A.F.M., Snyder, J., et al. Anatomical alterations of the visual motion processing network in migraine with and without aura, PLoS Medicine, 2006; 3(10): e402.

9190 Braunitzer, G., Roksin, A., Kóbor, J., et al. Delayed development of visual motion processing in childhood migraine, Cephalalgia, 2012; 32, 492-496.

| 9291 Webster, M. A., (2011). Adaptation and visual coding. Journal of Vision, 11(5): $1-23$.

93-92 Shepherd, A. J. Increased visual after-effects following pattern adaptation in migraine: A lack of intracortical excitation? Brain, 2001; 124(11): 2310-2318.

9493 Shepherd, A. J., Palmer, J. E., and Davis, G. Increased visual after-effects in migraine following pattern adaptation to tilt illusion. Spatial Vision, 2002; 16(1): 3343.

95-94 Battista, J., Badcock, D. R., and McKendrick, A. M. Centre-surround visual motion processing in migraine. Investigative Ophthalmology and Visual Science, 2010; 51(11): 6070-6076.

96-95 Tadin D, Lappin, J.S., Gilroy, L.S. et al. Perceptual consequences of centresurround suppression antagonism in visual motion processing. Nature, 2003; 424: 312-315.

96 Gerszstenkorn D, and Lee A. G., Palinopsia revamped: A systematic review of the literature. Survey of Ophthalmology, 2015; 60: 1-35.

97 Belcastro V., Cupini L. M., Corbelli I., Pieroni A., D’Amore C., Caproni S., et al. Palinopsia in patients with migraine: A case-control study. Cephalalgia, 2011; 31(9): 99-1004.

| 9798 Thabet, M., Wilkinson, F., Wilson, H. R., et al. The locus of flicker adaptation in the migraine visual system: A dichoptic study. Cephalalgia, 2012; 33(1): 5-19.

98-99 Coppola, G., Pierelli, F., and Schoenen, J. Is the cerebral cortex hyperexcitable or hyperresponsive in migraine? Cephalalgia, 2007; 27(12):1429-1439.

99-100 Zhaoping, L. Theoretical understanding of the early visual processes by data compression and data selection. Network: Computation in Neural Systems, 2006; 17(4): 301-334. 
$100-101$ Atick, J. J. Could information theory provide an ecological theory of sensory processing? Network, 1992; 3(2),: 213-251.

| 101-102 Aurora, S. K., and Wilkinson, F. The brain is hyperexcitable in migraine. Cephalalgia, 2007; 27(12): 1422-1435.

102103 Schoenen, J., Wang, W., Albert, A et al. Potentiation instead of habituation characterizes visual evoked potentials in migraine patients between attacks. European Journal of Neurology, 1995; 2(2): 115-22.

| 103-104 Mulleners, W. M., Chronicle, E. P., Palmer, et al. Visual cortex excitability in migraine with and without aura. Headache, 2001; 14: 565-572

| 104-105 Brighina, F., Palmero, A., and Fierro, B. Cortical inhibition and habituation to evoked potentials: Relevance for pathophysiology of migraine. Journal of Headache Pain, 2009; 10(2):77-82.

105-106 Lu, Z. L., and Dosher, B. A. Characterizing observers using external noise and observer models: Assessing internal representations with external noise. Psychological Review, 2008; 115(5): 44-82.

| 106-107 Georgeson, M. A., and Meese, T. S. Fixed or variable noise n contrast discrimination? The jury's still out... Vision Research, 2006; 46(25): 4294-303.

| 107 108 Klein, S. A. Separating transducer non-linearities and multiplicative noise in contrast discrimination. Vision Research, 2006; 46:4279-4293.

| 108-109 Kontsevich, L. L., Chen, C. C., Tyler, C. W. Separating the effects of response nonlinearity and internal noise psychophysically. Vision Research, 2002; 42:1771-1784.

| 109-110 May, K. A., and Solomon, J. A. Four theorems on the psychometric function. PLoS ONE, 2013a; 8(10): e74815.

110 111 May, K. A., and Solomon, J. A. Reconciling multiplicative psychological noise and additive psychophysical noise. Perception, 2013b; 42, ECVP abstract supplement, 158.

1 111 112 Baker, D. H. What is the primary cause of individual differences in contrast sensitivity? PLoS ONE, 2013; 8(7): e69536.

| 112113 Ohla, K. Busch, N. A., Dahlem, M. A., et al. Circles are different: The perception of Glass patterns modulates early event-related potentials. Vision Research, 2005; 45: 2668-2676.

113-114 Georgiades, M.S. and Harris, J.P. Attentional diversion during adaptation affects the velocity as well as the duration of motion aftereffects. Proceedings of the Royals Society of London B, 2000; 267: 2559-2565. 
114 115 Rankin, C. H., Abrams, T., Barry, R. J., et al. Habituation revisited: An updated and revised description of the behavioural characteristics of habituation. Neurobiology of Learning and Memory, 1992; 92: 135-138.

116 Vanagaite Vingen, J., Pareja, J. A., Støren, O., White, L. R., and Stovner, L. J. Phonophobia in migraine. Cephalalgia, 1998; 18(5): 243-249.

117 Schwedt T. J. Multisensory integration in migraine. Curr. Opin. Neurol., 2013; 26(3): 248-253.

118 Jensen, O., Gips, B., Bergmann, T. O., and Bonneford, M. Temporal coding organized by coupled alpha and gamma oscillations prioritize visual processing. Trends in Neurosciences, 2014; 37(7).

119 Dugue, L., Marque, P., and Van Rullen, R. The Phase of ongoing oscillations mediates the causal relation between brain excitation and visual perception. The Journal of Neuroscience. 2011; 31(33): 11889-11893.

120 Angekalis, E., Stathopoulou, S., Frymiare, J. L., Green, D. L., Lubar, J. F., and Kounios, J. EEG neurofeedback: A brief overview and an example of peak alpha frequency training for cognitive enhancement in the elderly. The Clinical Neuropsychologist, 2007; 21(1): 110-129.

121 Kober, S. E., Witte, M., Ninaus, M., Neurper, C., and Wood, G. Learning to modulate one's own brain activity: the effect of spontaneous mental strategies. Frontiers in Human Neuroscience, 2013; 7: 695.

122 Yang, W., Chu, B., Yang, J., Yu, Y., Wu, J., and Yu, S. Elevated audiovisual temporal interaction in patients with migraine without aura. The Journal of Headache and Pain, 2014; 15: 44

123 Lempert, T., Vestibular migraine. Semin Neurol., 2013; 33: 212-218.

124 Imaizumi, S., Honma, M., Hibino, H., and Koyama, S. Illusory visual motion stimulus elicits postural sway in migraine patients. Frontiers in Psychology, 2015; $\underline{\text { doi:10.3389/fpsyg.2015.00542 }}$

125 Marano, E., Marcelli, V., Di Stasio, E., Bonuso, S., Vacca, G., Manganelli, F., et al. Trigemineal stimulation elicits a peripheral vestibular imbalance in migraine patients. Headache, 2005: 45:325-331.

126 Chan, Y. C., Burgunder, J. M., Wilder-Smith, E., Chew, S. E., Lam-Mok-Sing, $\underline{\text { K., Sharma, V., et al. Electroencephalographic changes and seizures in familial }}$ hemiplegic migraine patients with the CACNA1A gene S218L mutation. Journal of Clinical Neuroscience, 2008; 15: 891-894.

127 van den Maagdenberg, A. M. J.M., Pizzorusso, T., Kaja, S., Terpolilli, N., Shapovalova, M., Hoebeek, F. E., et al. High cortical spreading depression susceptibility and migraine-associated symptoms in Cav2.1 S218L mice. Annals of Neurology, 2010; 67(1): 85-98 
128 Zangaladze, A., Asadi-Pooya, A. A., Ashkenazi, A., and Sperling, M. R. Sporadic hemiplegic migraine and epilepsy associated with CACNA1A gene mutation. Epilepsy and Behaviour, 2010; 17: 293-295.

129 Greenberg, D. A. Calcium channel antagonists and the treatment of migraine. Clin Neuropharmacol. 1986; 9(4): 311-328.

130 Pietrobon, D., Insights into migraine mechanisms and Cav2.1 calcuim channel function from mouse models of familial hemiplegic migraine. The Journal of Physiology, 2010; 588(11): 1871-1878.

131 Hoebeek, F., Stahl, J. S., van Alphen, A. N., Schonewille, M., Luo, C., Rutteman, M., et al. Increased noise level of Purkinje cell activities minimizes impact of their modulation during sensorimotor control. Neuron, 2005; 45(6): 953-965.

132 Engelhaaf, M., and Borst, A. A look into the cockpit of the fly: Visual orientation, algorithms, and identified neurons. The Journal of Neuroscience, 1993; 13(11): 4563-4574.

133 Zamponi, G. W., Lewis, R. J., Todorovic, S. M., Arneric, S. P., and Snutch, T. P. Role of voltage-gated calcium channels in ascending pain pathways. Brain Res Rev. 2009; 60(1): 84-89.

134 Thomsen, L. L., Eriksen, M. K., Roemer, S. F., Andersen, I., Olesen, J., and Russell, M. B. A population-based study of familial hemiplegic migraine suggests revised diagnostic criteria. Brain, 2002; 125(6): 1379-91.

| 115-135 Klein, R. M. Inhibition of return. Trends in Cognitive Neurosciences, 2000; 4(4), 138-147.

| 116-136 Omland, P. M., Nilsen, K. B., Uglem, M., et al. Visual evoked potentials in interictal migraine: No confirmation of abnormal habituation. Headache, 2013; 53: 1071-1086.

137 Schmitz, N., Admiraal-Behloul, F., Arkink, E. B., Kruit, M. C., Schoonman, G. G., Ferrari, M. D., et al. Attack frequency and disease duration as indicators for brain damage in migraine. Headache, 2008; 48(7): 1044-55.

138 Schwarz R. H., and Kern, R. Z. Migraine is associated with magnetic resonance imaging white matter abnormalities. Arch Neurol., 2004 61(9): 1366-1368.

139 Owen J. P., Marco E .J., Desai, S., Fourie, E., Harris, J., Hill, S. S., et al. Abnormal white matter microstructure in children with sensory processing disorders. NeuroImage: Clinical, 2013; 844-853.

140 Lockhart, S. N., Luck, S. J., Geng, J., Beckett, L., Disbrow, L. A., Carmichael, $\underline{\text { O., et al. White matter hypertensities among older adults are associated with futile }}$ increased in frontal activation and functional connectivity during spatial search. PLOS ONE 2015; 10(3). 
141 Wilkins, A. J., Patel, R., Adjamian, P., and Evans, B. J. Tinted spectacles and visually sensitive migraine. Cephalalgia, 2002; 22:711-9.

| 117 142 Dakin, S. D., and Baruch, N. J. Context influences contour integration. Journal of Vision, 2009; 9(13) 


\begin{tabular}{|c|c|c|c|c|}
\hline Study & Participants & Stimuli & Procedure & Finding \\
\hline $\begin{array}{l}\text { McColl and } \\
\text { Wilkinson } \\
(2000)\end{array}$ & $\begin{array}{l}25 \mathrm{C}(17 \mathrm{~F}) ; \text { average } \\
\text { age } 27.4 \mathrm{yr} \\
25 \mathrm{MA}(19 \mathrm{~F}) ; \\
\text { Average age } 30.7 \\
22 \mathrm{MO}(20 \mathrm{~F}) ; \\
\text { average age } 29.0 \mathrm{yr} \\
\text { Excluded if on } \\
\text { medication. } \\
7 \text { days attack free } \\
\text { before testing. }\end{array}$ & $\begin{array}{l}\text { 3cpd vertical } \\
\text { derivative of } \\
\text { Gaussian. } \\
30 \mathrm{~ms} . \\
2 \text { degrees of } \\
\text { visual angle. }\end{array}$ & $\begin{array}{l}\text { 2IFC } \\
\text { MOC } \\
\text { (5 targets, } 25 \\
\text { reps) } \\
75 \% \text { threshold. }\end{array}$ & $\begin{array}{l}\text { Trend towards } \\
\text { lower } \\
\text { thresholds in } \\
\text { migraine } \\
\text { groups but not } \\
\text { significant. }\end{array}$ \\
\hline $\begin{array}{l}\text { Shepherd } \\
(2000)\end{array}$ & $\begin{array}{l}35 \mathrm{C}(26 \mathrm{~F}) \\
25 \text { migraine }(12 \\
\mathrm{MA})(25 \mathrm{~F}) \\
\text { Average age } 40 . \\
\text { No acute } \\
\text { medication. } \\
48 \mathrm{~h} \text { since last } \\
\text { attack. } \\
2 \text { taking pizotifen. }\end{array}$ & $\begin{array}{l}\text { Cambridge } \\
\text { Low Contrast } \\
\text { Gratings at a } \\
\text { distance of } \\
6 \mathrm{~m} . \\
4 \mathrm{cpd} .\end{array}$ & $\begin{array}{l}\text { Staircase: Keep } \\
\text { going until you } \\
\text { make an error; } \\
\text { step back } 3 \\
\text { plates; stop after } \\
3 \text { errors. }\end{array}$ & $\begin{array}{l}\text { Control } \\
\text { significantly } \\
\text { better than } \\
\text { migraine } \\
\text { groups. }\end{array}$ \\
\hline $\begin{array}{l}\text { McKendrick et } \\
\text { al. (2001) }\end{array}$ & $15 \mathrm{MA} 15 \mathrm{C}$ & $\begin{array}{l}3.5 \mathrm{deg} \text { Gabor } \\
0.5 \mathrm{cpd} ; 16 \mathrm{~Hz} \text {; } \\
4 \mathrm{cpd}, 2 \mathrm{~Hz} \\
1 \mathrm{~s} \\
\text { presentation }\end{array}$ & $\begin{array}{l}\text { 2IFC. } \\
\text { 3-up 1-down } \\
\text { staircase. }\end{array}$ & $\begin{array}{l}\text { No differences } \\
\text { for either MA } \\
\text { or MO. }\end{array}$ \\
\hline $\begin{array}{l}\text { Benedek et al. } \\
(2002)\end{array}$ & $\begin{array}{l}15 \text { female MO (18- } \\
53 \mathrm{yr}) \text {, } \\
15 \text { age matched } \\
\text { female control. } \\
2 \text { week before/after } \\
\text { exclusion. } \\
\text { No mention of } \\
\text { medication. }\end{array}$ & $\begin{array}{l}\begin{array}{l}\text { Monocular } \\
\text { static and } \\
\text { dynamic } \\
\text { contrast } \\
\text { sensitivity. }\end{array} \\
\text { 0.5, 1.2, } 1.9 . \\
\text { 2.9. } 3.6,4.8, \\
7.2,14.3 \mathrm{cpd} . \\
\text { Dynamic } 4 \mathrm{~Hz} \\
13 \text { degree } \\
\text { square, } 1 \mathrm{~m} . \\
17 \text { or } 0.17 \\
\mathrm{~cd} / \mathrm{m}^{2}\end{array}$ & $\begin{array}{l}\text { Start at high } \\
\text { contrast; reduce } \\
\text { every 5s until the } \\
\text { participant cannot } \\
\text { see it. } \\
\text { Then use same } \\
\text { procedure to } \\
\text { increase contrast. } \\
5 \text { repetitions. }\end{array}$ & $\begin{array}{l}\text { Migraine } \\
\text { impairment, } \\
\text { especially at } \\
\text { low } \\
\text { frequencies } \\
\text { and with } \\
\text { scotopic } \\
\text { viewing } \\
\text { Posthoc: } \\
\text { Photopic } \\
\text { static: }(0.5- \\
3.5 \text { cpd) } \\
\text { Photopic } \\
\text { dynamic: (0.5- } \\
1.9) \\
\text { Scotopic } \\
\text { static: }(0.5- \\
14.3 \text { cpd) } \\
\text { Scotopic } \\
\text { dynamic: } \\
(0.5-3.5 \mathrm{cpd})\end{array}$ \\
\hline
\end{tabular}




\begin{tabular}{|c|c|c|c|c|}
\hline $\begin{array}{l}\text { Tibber et al. } \\
\text { (2006) }\end{array}$ & $\begin{array}{l}\text { 10MA 10MO 20C } \\
-48 /+24 \text { h exclusion. } \\
\text { No acute } \\
\text { medication. } \\
\text { No daily } \\
\text { medication. }\end{array}$ & $\begin{array}{l}\text { Gabor patches } \\
25 \mathrm{~ms} \text { interval } \\
0, \text { and } 45 \mathrm{deg} \\
\text { orientation } \\
4 \mathrm{cpd}, 1.6 \mathrm{deg}\end{array}$ & $\begin{array}{l}\text { 2-down 1-up } \\
\text { staircase 2IFC. }\end{array}$ & $\begin{array}{l}\text { No group } \\
\text { difference. }\end{array}$ \\
\hline $\begin{array}{l}\text { Yenice et al. } \\
\text { (2007) }\end{array}$ & $\begin{array}{l}28 \mathrm{M} 15 \mathrm{C} \\
1 \text { week after last } \\
\text { episode. } \\
\begin{array}{l}\text { No mention of } \\
\text { medication. }\end{array} \\
\end{array}$ & $\begin{array}{l}\text { Functional } \\
\text { Acuity } \\
\text { Contrast Test, } \\
1.5361218 \\
\text { cpd, } \\
1.7 \mathrm{deg} .\end{array}$ & $\begin{array}{l}\text { Orientation } \\
\text { discrimination } \\
( \pm 5 \text { or } 0) .\end{array}$ & $\begin{array}{l}\text { Worse } \\
\text { performance } \\
\text { in migraine at } \\
\text { all } \\
\text { frequencies. }\end{array}$ \\
\hline $\begin{array}{l}\text { McKendrick } \\
\text { and Sampson } \\
\text { (2009) }\end{array}$ & $\begin{array}{l}17 \mathrm{C}(18-35 \mathrm{yr}) 6 \\
\text { female, } \\
12 \mathrm{M}(19-44 \mathrm{yr}) 4 \\
\text { female. } \\
\text { No migraine } \\
\text { medication. } \\
4 \text { days post } \\
\text { migraine. }\end{array}$ & $\begin{array}{l}\text { Gabor } \\
\text { (envelope } \\
2.66 \mathrm{deg} \text { ) } \\
0.25,0.5,1,2 \\
4 \mathrm{cpd}, \\
\pm 45 \mathrm{deg}, \\
30 \mathrm{~ms} . \\
\text { Central and } \\
\text { mid- } \\
\text { peripheral } \\
\text { (10deg). } \\
\text { Steady and } \\
\text { pulsed } \\
\text { pedestal (i.e. } \\
\text { mean } \\
\text { luminance } \\
\text { change). }\end{array}$ & $\begin{array}{l}\text { 2AFC orientation } \\
\text { 3-down 1-up } \\
\text { staircase } \\
\text { (reversals not } \\
\text { psychometric } \\
\text { functions used). }\end{array}$ & $\begin{array}{l}\text { Central } \\
\text { presentation: } \\
\text { no significant } \\
\text { group effect } \\
\text { (but migraine } \\
\text { worse). } \\
\text { Peripheral } \\
\text { presentation: } \\
\text { poorer } \\
\text { performance } \\
\text { in migraine } \\
\text { group. }\end{array}$ \\
\hline $\begin{array}{l}\text { Braunitzer et al. } \\
(2010)\end{array}$ & $\begin{array}{l}\text { 6-10 yr. } \\
10-12 \mathrm{yr} . \\
12-14 \mathrm{yr} . \\
6 \text { control/migraine } \\
\text { each group. } \\
\text { Between } 1 \text { and } 7 \\
\text { days after attack. } \\
\text { No medication. }\end{array}$ & $\begin{array}{l}\text { Replication of } \\
\text { Benedek, et } \\
\text { al. }(2002) \\
\text { photopic } \\
\text { dynamic. } \\
8 \mathrm{~Hz} \text {. } \\
1.2 \& 1.9 \mathrm{cpd}\end{array}$ & $\begin{array}{l}\text { Same method as } \\
\text { Benedek et al. } \\
(2002) \text {. }\end{array}$ & $\begin{array}{l}\text { No differences } \\
\text { for } 6-10 \mathrm{yr} \text {. } \\
\text { Significantly } \\
\text { worse } \\
\text { performance } \\
\text { for } 10-12 \mathrm{yr} \\
\text { and } 12-14 \mathrm{yr} \text {. }\end{array}$ \\
\hline $\begin{array}{l}\text { Mendes et al. } \\
\text { (2011) }\end{array}$ & $\begin{array}{l}\text { 2MA 4MO 6C. } \\
\text { All female 20-37yr. } \\
\text { Some taking anti- } \\
\text { migraine drugs. } \\
\text { Not using }\end{array}$ & $\begin{array}{l}\text { Angular sine } \\
\text { wave (sine } \\
\text { function of } \\
\text { orientation), } \\
2,3,4,24,64 \\
\text { cycles/circle, } \\
7 \mathrm{deg} \text {. }\end{array}$ & $\begin{array}{l}\text { 2AFC } \\
\text { present/absent } \\
\text { 3-down 1-up } \\
\text { staircase. }\end{array}$ & $\begin{array}{l}\text { Migraine } \\
\text { show poorer } \\
\text { performance } \\
\text { effect at } 2,4 \text {, } \\
24,64 \text { (just } \\
\text { not } 3 \mathrm{cpd} \text { ) }\end{array}$ \\
\hline
\end{tabular}




\begin{tabular}{|c|c|c|c|c|}
\hline & $\begin{array}{l}\text { medication, or } \\
\text { attack, for } 48 \mathrm{~h} \text {. }\end{array}$ & & & \\
\hline $\begin{array}{l}\text { Wagner et al. } \\
\text { (2010) }\end{array}$ & $\begin{array}{l}10 \mathrm{C} 10 \mathrm{MA} 10 \mathrm{MO} \\
\text { No medication of } \\
\text { migraine }+/-3 \text { days } \\
\text { of testing. }\end{array}$ & $\begin{array}{l}0.25 \text { deg disc } \\
\text { against grey } \\
\text { background. }\end{array}$ & $\begin{array}{l}\text { Staircase, spatial } \\
\text { 2AFC, 1.8deg } \\
\text { apart. }\end{array}$ & $\begin{array}{l}\text { No group } \\
\text { difference in } \\
\text { thresholds. }\end{array}$ \\
\hline $\begin{array}{l}\text { Webster et al. } \\
\text { (2012) }\end{array}$ & $\begin{array}{l}\text { 6MA 5MO 12C } \\
(20-40 \mathrm{yr}) . \\
\text { No preventative } \\
\text { medication. } \\
\pm 3 \text { day exclusion. }\end{array}$ & $\begin{array}{l}1.5 \text { deg disc, } \\
\text { similar to } \\
\text { Wagner et al. } \\
(2010)\end{array}$ & $\begin{array}{l}\text { Staircase } \\
\text { Spatial 2AFC (1 } \\
\text { target one blank) }\end{array}$ & $\begin{array}{l}\text { No group } \\
\text { difference in } \\
\text { thresholds. }\end{array}$ \\
\hline $\begin{array}{l}\text { Shepherd et al. } \\
\text { (2013) }\end{array}$ & $\begin{array}{l}\text { 14 MA (24.6yr) } \\
14 \text { MO (24.6yr) } \\
14 \mathrm{C}(23.1 \mathrm{yr}) \\
\text { 48h either side free } \\
\text { from migraine } \\
\text { attack and acute } \\
\text { medication. } \\
\text { None taking daily } \\
\text { medication. }\end{array}$ & $\begin{array}{l}\text { Cambridge } \\
\text { Low Contrast } \\
\text { Gratings, } \\
4 \text { cpd. }\end{array}$ & $\begin{array}{l}\text { Keep going until } \\
\text { error made; step } \\
\text { back } 3 \text { plates; } \\
\text { stop after } 3 \text { errors }\end{array}$ & $\begin{array}{l}\text { Significantly } \\
\text { higher } \\
\text { thresholds in } \\
\text { migraine } \\
\text { groups. }\end{array}$ \\
\hline
\end{tabular}

Table 1: A summary of the literature on contrast sensitivity in migraine. Key of abbreviations: $M A=$ migraine-with-aura, $M O=$ migraine-without-aura, $C=$ control, $M O C$ $=$ method of constant stimuli, $2 I F C=$ two-interval-forced-choice, photopic $=$ full light levels, scotopic $=$ reduced light levels. 


\begin{tabular}{|c|c|c|c|c|}
\hline Study & Participants & Stimuli & Procedure & Finding \\
\hline Antal et al. (2005) & $\begin{array}{l}\text { 11MA 9MO 20C } \\
\text { No medication. } \\
\text { Headache free -/+ } \\
3 \text { days. }\end{array}$ & $\begin{array}{l}10 \times 10 \mathrm{deg} \\
\text { RDK, } 72 \mathrm{~ms}, \\
5 \mathrm{deg} / \mathrm{s} \\
\text { With noise } \\
\text { dots and } \\
\text { without } \\
\text { (detection of } \\
\text { motion only) }\end{array}$ & $\begin{array}{l}6 \text { staircase } \\
\text { reversals, } \\
\text { MOCS. }\end{array}$ & $\begin{array}{l}\text { MA and MO } \\
\text { significantly } \\
\text { higher } \\
\text { thresholds } \\
\text { than controls. } \\
\text { Motion } \\
\text { detection } \\
\text { worse in MA } \\
\text { also. }\end{array}$ \\
\hline $\begin{array}{l}\text { McKendrick et al. } \\
\text { (2006) }\end{array}$ & $\begin{array}{l}\text { 20C 17MA } 13 \text { MO } \\
\text { No medication } \\
\text { Headache free } 4 \\
\text { days before, and } \\
72 \text { hours after } \\
\text { testing }\end{array}$ & $\begin{array}{l}\text { Spiral } \\
\text { random dot } \\
\text { pairs, } \\
\text { decrease } \\
\text { pairs. } \\
\text { Downward } \\
\text { RDK 3deg/s, } \\
\text { motion } \\
\text { coherence } \\
\text { threshold. } \\
\end{array}$ & 2IFC & $\begin{array}{l}\text { Migraine } \\
\text { thresholds } \\
\text { elevated } \\
\text { compared to } \\
\text { control for } \\
\text { global motion } \\
\text { and form. }\end{array}$ \\
\hline $\begin{array}{l}\text { Ditchfield et al. } \\
\text { (2006) }\end{array}$ & $\begin{array}{l}10 \mathrm{MO} 9 \mathrm{MA} 16 \mathrm{C} \\
4 \text { days after attack. } \\
\text { No medication that } \\
\text { affects CSF. }\end{array}$ & $\begin{array}{l}\text { Spiral made } \\
\text { of dot pairs, } \\
\text { Downward } \\
\text { RDK, } \\
2.83 \mathrm{deg} / \mathrm{s}, \\
\text { nothing } \\
\text { within } 10 \mathrm{deg} \\
\text { of signal. }\end{array}$ & $\begin{array}{l}\text { 2IFC, 3-down 1- } \\
\text { up staircase. }\end{array}$ & $\begin{array}{l}\text { Migraine } \\
\text { worse than } \\
\text { control for } \\
\text { both motion } \\
\text { and form. }\end{array}$ \\
\hline $\begin{array}{l}\text { Webster et al. } \\
\text { (2011) }\end{array}$ & $\begin{array}{l}6 \mathrm{MA}, 5 \mathrm{MO}, 12 \mathrm{C} \\
\text { No medication. } \\
4 \text { days since last } \\
\text { attack. }\end{array}$ & $\begin{array}{l}\text { Gabor } \\
\text { patches, } 3.75 \\
\text { cpd gratings, } \\
\text { cosine phase. }\end{array}$ & $\begin{array}{l}\text { Detect deviation } \\
\text { from circle. } \\
\text { Detect spiral } \\
\text { path. }\end{array}$ & $\begin{array}{l}\text { Migraine } \\
\text { worse at } \\
\text { detecting } \\
\text { deviation } \\
\text { from circle. } \\
\text { No group } \\
\text { difference to } \\
\text { find spiral } \\
\text { path, with or } \\
\text { without noise. }\end{array}$ \\
\hline $\begin{array}{l}\text { Braunitzer et al. } \\
(2012)\end{array}$ & $\begin{array}{l}\text { Only over-counter } \\
\text { pain killers. } \\
\text { Tested } \\
\text { 'interictically'. } \\
\text { 14MO 21C. } \\
\text { 8-17 year olds. }\end{array}$ & $\begin{array}{l}4.4 \text { deg for } \\
0.8 \text { s. } 100 \\
\text { dots, } 10 \\
\text { pixels, } \\
\text { percentage } \\
\text { change }\end{array}$ & $\begin{array}{l}\text { Quest adaptive } \\
\text { staircase, left or } \\
\text { right movement. }\end{array}$ & $\begin{array}{l}\text { Controls had } \\
\text { lower } \\
\text { thresholds } \\
\text { than migraine. }\end{array}$ \\
\hline $\begin{array}{l}\text { Wagner et al. } \\
\text { (2013) }\end{array}$ & $\begin{array}{l}\text { 9C 9MO 9MA } \\
\text { Headache free }+/-3 \\
\text { days. } \\
\text { No medication. }\end{array}$ & $\begin{array}{l}\text { Radial form } \\
\text { task to } \\
\text { discriminate } \\
\text { deviation } \\
\text { from a circle. } \\
\text { Mask is a } \\
\text { flower shape } \\
(15 \% \\
\text { deviation }\end{array}$ & $\begin{array}{l}\text { Determine if } \\
\text { same or } \\
\text { different from } \\
\text { standard } \\
\text { (circle), 2IFC } \\
\text { with masking in } \\
\text { between. } \\
\text { Different SOA: } \\
0,50,100,150 \text {, }\end{array}$ & $\begin{array}{l}\text { Thresholds } \\
\text { higher for MA } \\
\text { compared to } \\
\text { control, max } \\
\text { when SOA } \\
\text { approx. 50- } \\
\text { 100ms. }\end{array}$ \\
\hline
\end{tabular}




\begin{tabular}{|l|l|l|l|l|}
\hline & & from circle). & 200,250 & \\
\hline Tibber et al. (2014) & 12MA 10MO 22C & $100 \mathrm{dots}$, & Quest adaptive & Motion \\
& No medication. & $400 \mathrm{~ms}$ & staircase, & coherence \\
& $\begin{array}{l}\text { No mention of } \\
\text { time of testing. }\end{array}$ & $\begin{array}{l}\text { against } \\
\text { grey.3deg/s, } \\
50 \% \text { contrast }\end{array}$ & $\begin{array}{l}\text { percentage of } \\
\text { dots as signal } \\
\text { needed. }\end{array}$ & $\begin{array}{l}\text { predicted by } \\
\text { pooling. }\end{array}$ \\
\hline
\end{tabular}

Table 2: A summary of the literature on global integration tasks in migraine. Key of abbreviations: $M A=$ migraine-with-aura, $M O=$ migraine-without-aura, $C=$ control, $2 A F C$ $=$ two-alternative-forced-choice, $M O C=$ method of constant stimuli, SOA = stimulus onset asynchrony, $C S F=$ contrast sensitivity function, $R D K=$ random dot kinematogram . 


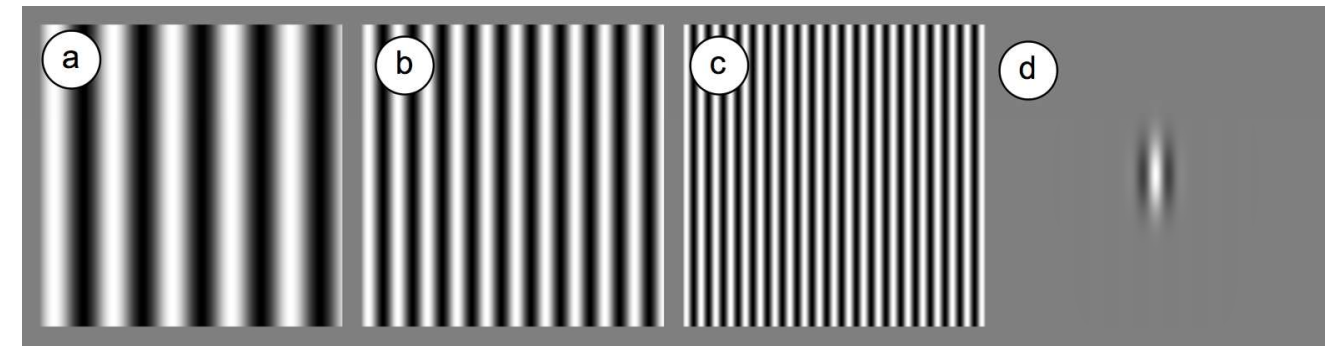

Figure 1: (a)-(c) gratings with progressively increasing spatial frequency. (d) A Gabor patch stimulus, which is a sine grating multiplied by a Gaussian envelope.

$712 \times 185 \mathrm{~mm}(72 \times 72 \mathrm{DPI})$ 
Figure 3: An illustration of an association field of the type proposed by Field et al. (1993), adapted from Dakin and Baruch (2009). Each circle represents the receptive field of an orientation-tuned neuron. Excitatory connections (solid lines) exist between neurons whose position and orientation tuning are consistent with smooth, continuous contours. Inhibitory connections (dashed lines) exist between neurons whose orientation tuning is inconsistent with smooth, continuous contours. $176 \times 101 \mathrm{~mm}(300 \times 300 \mathrm{DPI})$ 

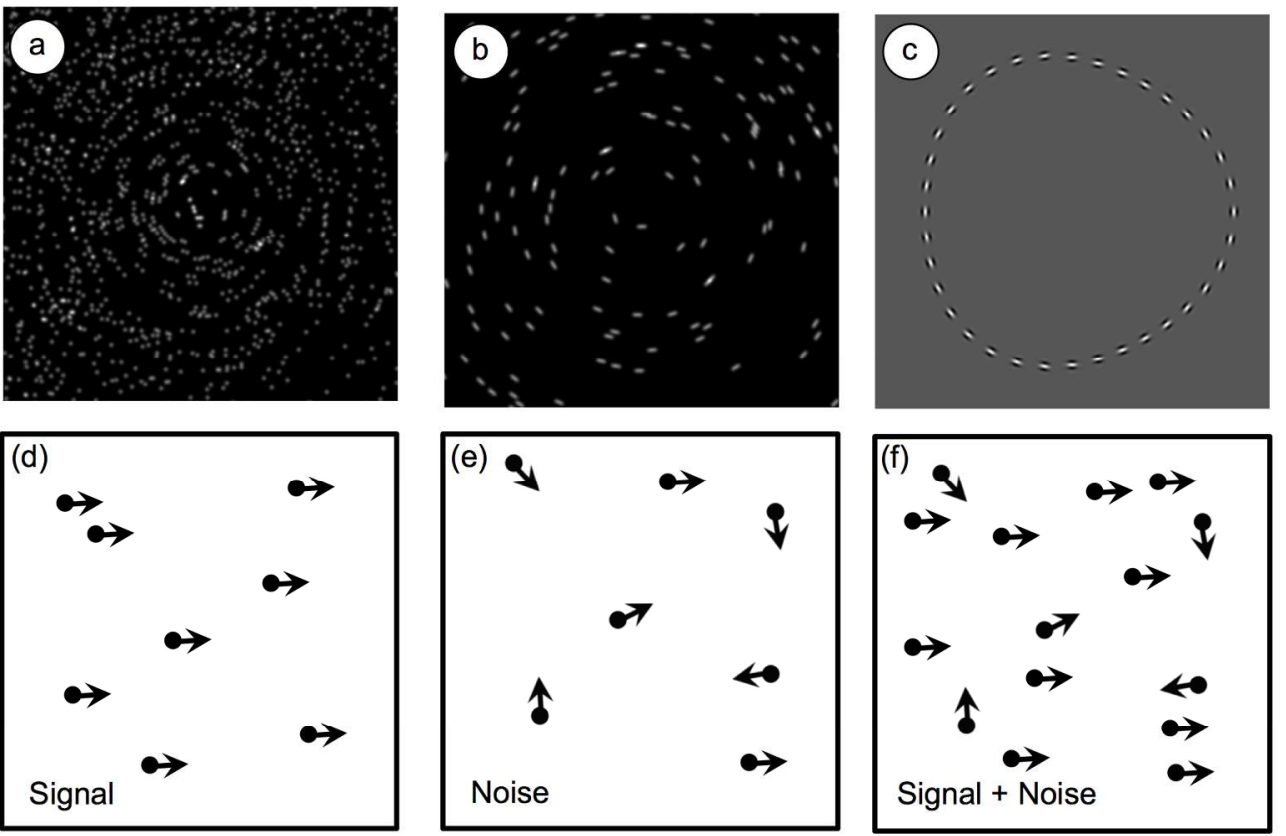

Figure 4: Stimuli used in the perception of global form and motion (a) A Glass pattern, in which a random dot pattern, and a rotated version of the pattern, are combined, given the appearance of a circular structure. (b) A Glass line pattern in which the structure is determine by oriented lines, rather than pairs of dots (c) The global shape task used by Webster et al. (2012), in which observers were asked to detect deviations from a circular contour, as shown here. (d)-(f) illustrate the construction of a typical global motion stimulus. (e) Signal dots that are all moving in the same direction, in this case to the right. (f) Noise dots, moving in randomly chosen direction. (f) A typical stimulus in which signal and noise dots are combined and observers are asked to judge whether the overall direction is rightwards or leftwards.

$178 \times 117 \mathrm{~mm}(300 \times 300$ DPI $)$ 
Figure 5: The signal processing model outlined in Equations 1 and 2. The input signal is transformed by the encoding function. The resulting output is the sum of the transformed signal and additive and (in Equation 2) multiplicative noise. The amplitude of the latter depends on the amplitude of the input signal. $173 \times 82 \mathrm{~mm}(300 \times 300 \mathrm{DPI})$ 


\section{MOOSE Checklist - to be submitted with your paper}

Cephalalgia required checklist for Meta-analysis of Observational Studies in Epidemiology MOOSE checklist

Title of Paper:

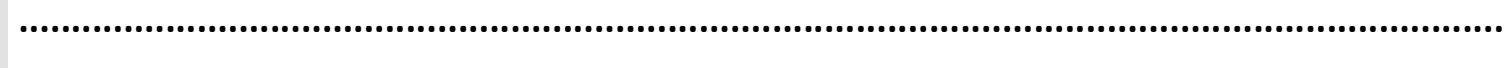

\section{Corresponding author:}

\begin{tabular}{|c|c|c|c|}
\hline & Reporting of background should include: & $\begin{array}{l}\text { item reported? } \\
\text { (Yes, No) }\end{array}$ & $\begin{array}{l}\text { Note page } \\
\text { number }\end{array}$ \\
\hline 1 & Problem definition & yes & 1 \\
\hline 2 & Hypothesis statement & Yes & 1 \\
\hline 3 & Description of study outcome(s) & No & \\
\hline 4 & Type of exposure or intervention used & No & \\
\hline 5 & Type of study designs used & Yes & $\begin{array}{l}4 \text { - psychophysical } \\
\text { studies }\end{array}$ \\
\hline \multirow[t]{2}{*}{6} & Study population & Yes & 1 \\
\hline & Reporting of search strategy should include: & & \\
\hline 7 & Qualifications of searchers (eg, librarians and investigators) & No & \\
\hline 8 & $\begin{array}{l}\text { Search strategy, including time period included in the synthesis } \\
\text { and keywords }\end{array}$ & No & \\
\hline 9 & $\begin{array}{l}\text { Effort to include all available studies, including contact with } \\
\text { authors }\end{array}$ & Yes & \\
\hline 10 & Databases and registries searched & No & \\
\hline 11 & $\begin{array}{l}\text { Search software used, name and version, including special } \\
\text { features used (eg, explosion) }\end{array}$ & No & \\
\hline 12 & Use of hand searching (eg, reference lists of obtained articles) & No & \\
\hline 13 & List of citations located and those excluded, including justification & yes & \\
\hline 14 & $\begin{array}{l}\text { Method of addressing articles published in languages other than } \\
\text { English }\end{array}$ & No & \\
\hline \multirow[t]{2}{*}{15} & Description of any contact with authors & No & \\
\hline & Reporting of methods should include: & & \\
\hline 16 & $\begin{array}{l}\text { Description of relevance or appropriateness of studies assembled } \\
\text { for assessing the hypothesis to be tested }\end{array}$ & Yes & 1 \\
\hline 17 & $\begin{array}{l}\text { Rationale for the selection and coding of data (eg, sound clinical } \\
\text { principles or convenience) }\end{array}$ & No & \\
\hline 18 & $\begin{array}{l}\text { Documentation of how data were classified and coded (eg, } \\
\text { multiple raters, blinding, and interrater reliability) }\end{array}$ & No & \\
\hline 19 & Assessment of confounding (eg, comparability of cases and & Yes & $3 / 4$, cycle effects \\
\hline
\end{tabular}




\begin{tabular}{|c|c|c|c|}
\hline \multicolumn{2}{|r|}{ Reporting of results should include: } & & \\
\hline 24 & $\begin{array}{l}\text { Graphic summarizing individual study estimates and overall } \\
\text { estimate }\end{array}$ & No & \\
\hline 25 & Table giving descriptive information for each study included & Yes & 4,7 table references \\
\hline 26 & Results of sensitivity testing (eg, subgroup analysis). & No & \\
\hline 27 & Indication of statistical uncertainty of findings & No & \\
\hline \multicolumn{2}{|r|}{ Reporting of discussion should include: } & & \\
\hline 28 & Quantitative assessment of bias (eg, publication bias) & No & \\
\hline 29 & $\begin{array}{l}\text { Justification for exclusion (eg, exclusion of non-English-language } \\
\text { citations) }\end{array}$ & No & \\
\hline 30 & Assessment of quality of included studies & No & \\
\hline \multicolumn{2}{|r|}{ Reporting of conclusions should include: } & & \\
\hline 31 & Consideration of alternative explanations for observed results & Yes & 3 and 4 cycle effects \\
\hline 32 & $\begin{array}{l}\text { Generalization of the conclusions (ie, appropriate for the data } \\
\text { presented and within the domain of the literature review) }\end{array}$ & Yes & 3 and 4, cycle effects \\
\hline 33 & Guidelines for future research & Yes & $\begin{array}{l}12-\text { need for model } \\
\text { development }\end{array}$ \\
\hline 34 & Disclosure of funding source & No & Not applicable \\
\hline
\end{tabular}

Adapted from:

Stroup,DF, Berlin, JA, Morton, SC, et al. Meta-analysis of Observational Studies in Epidemiology A Proposal for Reporting. JAMA, April 19, 2000-Vol 283, No. 15

Cephalalgia author guidelines require a copy of this completed checklist for meta-analyses of observational studies. Upload the document along with your manuscript submission. As a reminder, manuscript submissions are required to have separate files for the main body, tables, 
figures and checklists. Checklists are considered supporting documentation in the Cephalalgia manuscript dropdown box category. 